Secuencia (2003), 57, septiembre-diciembre, 125-156

ISSN: 0186-0348, ISSN electrónico: 2395-8464

DOI: http://dx.doi.org/10.18234/secuencia.v0i57.827

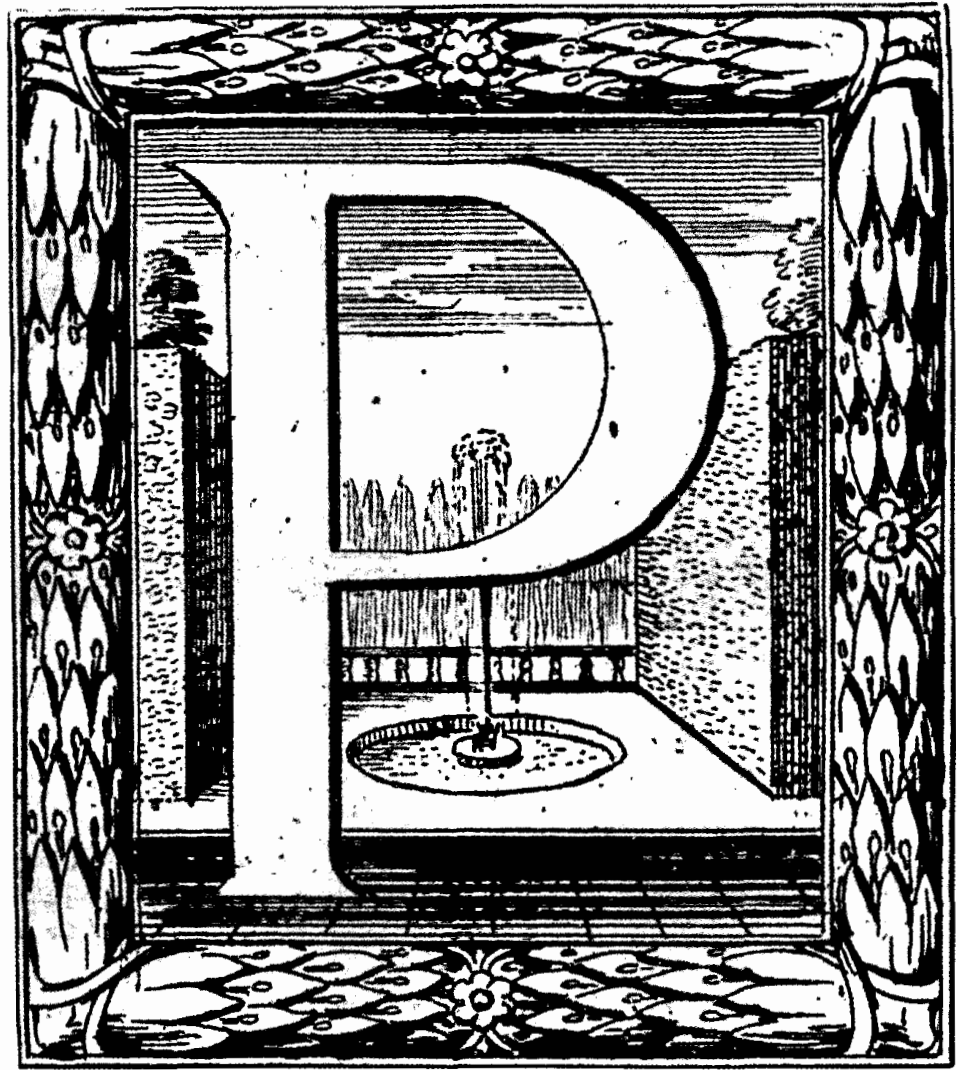




\section{Joel Outtes / Irene Kazumi Miura}

Joel Outtes. Doctor por la University of Oxford y posdoctorado por la Oxford Brookes University. Actualmente es profesor-investigador de la Universidade Federal do Rio Grande do Sul en Porto Alegre, Brasil. Sus temas de investigación son la historia urbana, la geografía urbana, la teoría social y la planificación urbana. El presente artículo ganó el Harold Blakemore Essay Prize de la British Society for Latin American Studies y la Cultural Geography Paper Competition de la Association of American Geographers en 2002.

Irene Kazumi Miura. Profesora y doctora de los cursos de grado, posgrado y MBA's de la Faculdade de Economia, Administração e Contabilidade de la Universidade de São Paulo. Maestra en Psicología Social por el Instituto de Psicología de la USP y doctora en Administración por la Faculdade de Economia, Administração e Contabilidade de la USP. Durante su doctorado fue investigadora visitante en el Judge Institute of Management de la University of Cambridge en Inglaterra. Sus temas de investigación son las cuestiones culturales, las migraciones internacionales y el comportamiento organizacional internacional.

\section{Resumen}

El artículo busca la génesis de un discurso sobre urbanismo (planeación de ciudades) en Brasil y Argentina entre 1894 y 1945 usando las ideas de Michel Foucault sobre disciplina y el concepto de biopoder. También se examinan los planes propuestos para las mismas ciudades en los años 1920 y a las representaciones urbanas, como son las ideas sobre reforma social, el papel de la higiene como punto de partida para la planeación, y la relación de ideas sobre taylorismo (administración científica) y la ciudad. Otros temas son el uso del urbanismo como elemento constructivo de las naciones y las ideas que definen eugenesia (mejoría de raza) como un aspecto importante del urbanismo. Concluyo argumentando que, si se implantara, el urbanismo sería una forma de crear una cultura industrial, disciplinando a la sociedad mediante la ciudad, aun cuando el proletariado industrial nunca ha sido la mayoría de la población en Brasil o Argentina.

\section{Palabras clave:}

Relaciones culturales, historia internacional, Foucault, urbanismo, América Latina, Brasil, Argentina, Río de Janeiro, Buenos Aires, São Paulo.

\section{Abstract}

This paper examines the origins of the discourse concerning ciry planning in Brazil and Argentina between 1894 and 1945, using Michel Foucault's ideas on discipline and his concept of bio-power. The paper also discusses the plans proposed for the same cities in the 1920s and to urban representations, such as ideas on social reform, the role of hygiene as the starting point for planning, and the relationship between Taylorist ideas (scientific management) and the city. Other issues in the paper include the use of planning as a feature of nation building and ideas on eugenics (hereditary improvement of the human race by selective breeding) as an important aspect of city planning. The author concludes by arguing that, if implemented, city planning was a way of creating an industrial culture and disciplining society through the city, although the industrial proletariat has never constitured the majority of the population in Brazil or Argentina.

\section{Key words:}

Cultural relations, international history, Foucault, city planning, Latin America, Brazil, Argentina, Rio de Janeiro, Burenos Aires, São Paulo.

Fecha de recepción: agosto de 2002

Fecha de aceptación: enero de 2003 


\title{
Disciplinar a la sociedad por medio de la ciudad: la génesis del urbanismo en Brasil y Argentina (1894-1945)*
}

\author{
Joel Outtes** \\ Irene Kazumi Miura
}

\section{INTRODUCCIÓN}

$\mathbf{E}$ n Brasil, la aparición del urbanismo tuvo lugar en el mismo periodo en que el gobierno empezó a intervenir en cuestiones sociales por medio de la creación de una legislatura laboral y políticas de bienestar. Según Foucault, el conocimiento, el discurso y el poder están

* Traducción de Sergio Fernández Bravo.

** Para un análisis más detallado del movimiento urbanista como una nueva profesión y conocimiento en Brasil y Argentina en la primera mitad del siglo xx, véase Outtes, "Ville", 1993. Agradezco a Christian Topalov por la supervisión de esa tesis, y a Colin Clarke, Mariano Plotkin, Nancy Leys Stepan, Mark Whitaker y Leslie Bethell por la lectura previa de esta ponencia. Deseo también dar las gracias a Claudio Lomnitz y a los estudiantes graduados en Historia de América Latina en la Universidad de Chicago; Peter Marcuse y los estudiantes graduados en Planeación Urbana en la Universidad de Columbia; Odete Seabra, Heiz Dieterman, Amélia Damiani y Ana Fani Alessandri Carlos en el Laboratorio de Geografía Urbana en la Universidad de São Paulo; y Luiz de la Mora, Circe Monteiro y los estudiantes en el Programa de Desarrollo Urbano y Regional en la Universidad Federal de Pernambuco, en donde se discutió esta ponencia. Para un análisis detallado y completo del urbanismo como una nueva profesión y conocimiento en Brasil, véase Outtes, "Diciplining", fuertemente asociados. ${ }^{1} \mathrm{El}$ pensamiento de Foucault contiene rasgos que se podrían aplicar o desarrollar para una historia del urbanismo. Según Foucault, no hay verdad en ningún discurso. Hay lo que él llamó efectos de verdad (resultados), producidos dentro de los discursos, que no son ni verdaderos ni falsos. ${ }^{2}$ En el caso del urbanismo, la creación de instituciones como las Comisiones o Juntas de Planificación de la Ciudad encargadas de planificar y controlar el crecimiento urbano dentro del aparato estatal, pueden considerarse como estos efectos de verdad. Hubo cambios desde principios de siglo hasta los años 1920 en el movimiento urbanista sudamericano. En sólo unos años el concepto de urbanismo se extendió de intervenciones aisladas en partes específicas del territorio urbano, hasta la urbani-

1999. Agradezco a David Harvey y a Colin Clarke la supervisión de esta última tesis. Todas las traducciones del español y del portugués son mías. Uso lenguaje de géneros según el género de los autores. Esto significa que cada vez que se usa el pronombre masculino se refiere a un autor, así como cada vez que se usa el pronombre femenino se refiere a una autora.

${ }^{1}$ Foucault, "Verité, 1977, pp. 4-5.

${ }^{2}$ Foucault, "Politics", 1968; "Verité", 1977. 
zación de ciudades en su totalidad y al control del crecimiento urbano. En vez de reparar lo que se había desarrollado en forma inadecuada, apareció la idea de crear reglas para forzar que las cosas pasaran de una manera predefinida.

Foucault criticó algunas interpretaciones tradicionales de poder, bien porque estaban centradas en la cuestión de soberanía o en aspectos jurídicos, o bien porque el poder era analizado desde un punto de vista marxista, en términos del aparato estatal. El problema de cómo era ejercido en términos concretos, en sus detalles, con su especificidad, sus técnicas y tácticas, no era tomado en consideración en las explicaciones previas. Es con base en esta consideración que Foucault desarrolla el concepto de biopoder, un concepto de poder relacionado con represiones concretas de los aspectos del cuerpo humano, como movimiento, libertad de ir y venir, salud, juventud, edad, sexualidad, etc. Este concepto explica, al menos parcialmente, su interés en temas como prisiones, hospitales, asilos y casas de labor en donde esa idea podría ser comprobada, observada y medida.

Por otra parte, el uso de este concepto sólo para el análisis de las relaciones en el interior de este tipo de instituciones, muestra la debilidad y limitación de semejante propuesta. La cuestión que persiste de la percepción de esta limitación es cómo o hasta dónde puede usarse este tipo de enfoque para el análisis del urbanismo. De hecho, las decisiones urbanistas tienen un impacto directo en el cuerpo humano. La clausura de ciertas áreas para algunas actividades, por ejemplo, es una limitación de la libertad de movimiento. Una decisión de este tipo es una restricción para el cuerpo infinitamente leve, sien- do por lo tanto un tipo de biopoder. En otras palabras, las decisiones de crear zonas limitadas, como el uso restringido de áreas, la prohibición de estacionarse en ciertas calles, la destinación de partes de una costa para la descarga de barcos en vez de para nadar, todo tiene efecto sobre la libertad individual. Si una prisión es un sitio en donde la libertad está completamente suprimida, una zona restrictiva es un lugar en donde la libertad está ligeramente disminuida.

Foucault afirma que si el poder fuera sólo represivo, si sólo dijera "no" todo el tiempo, no sería obedecido. Dice que lo que mantiene el poder y lo hace aceptable es el hecho de que produce cosas, induce placeres, conforma el conocimiento y produce discursos. Debería ser considerado como una red productiva que cruza todo el cuerpo social más que una instancia negativa que tiene la represión como su función. Según Foucault, la represión es más costosa y menos efectiva que la implantación de tecnologías para inducir el comportamiento. Aun cuando no da alguna evidencia estadística o cuantitativa sobre ello, por lo cual ha sido criticado más de una vez, en especial por los historiadores, ${ }^{3}$ se dan algunas sugerencias que son apropiadas para la planeación de ciudades. La aplicación del urbanismo es una forma aceptable de poder que produce cosas y da forma al conocimiento. Todos

${ }^{3}$ Para una crítica sobre el trabajo de Foucault por un historiador véase Poster, "Foucault", 1982, y Léonard, "Historien", 1980. Para una discusión de Foucault y los historiadores franceses véase Foucault, "Poussière", 1980. Para una respuesta brillante a la crítica de Leonard, véase Foucault, "Table", 1980. Otras referencias de relevancia para esta obra incluyen Driver, "Bodies", 1994; Eley y Nield, "Starting", 1995; Noiriel, "Foucault", 1994, y Palmer, Descent, 1990. 
los textos de planeación de ciudades y sus técnicas son una prueba de ello. Desarrollaré estas ideas para el caso de planeación de ciudades en Brasil, empezando con la siguiente cita:

Urbanizar ${ }^{4}$ es facilitar, disciplinar, embellecer, dar al hombre los elementos de una vida que lo distingue cada vez más de las eras inferiores iniciales de la comunidad urbana. La urbanización de la ciudad dará al Ayuntamiento los medios para elevar los estándares de vida de la gente, para construir casas y para proteger a la ciudad de vergonzosos barrios pobres. ${ }^{5}$

Con estas palabras, José Campelo, periodista y miembro de la Comisión de Urbanismo de Recife, celebró la publicación de un plan para la renovación del centro de esta ciudad de Brasil en 1938. Las ideas de este discurso no son suyas. Pongamos otro ejemplo. Otro reformista social, otra ciudad, otra fecha: Marcelo Mendonça, ingeniero y uno de los fundadores del Instituto Central de Arquitetos en Río de Janeiro, al presentar una ponencia en São Paulo en el Primeiro Congresso de Habitação en 1931, expresaba lo mismo:

El visitar los barrios pobres de la capital federal es suficiente para tener una idea clara

${ }^{4}$ Urbanizar es utilizado aquí en el sentido de intervenir en la ciudad para mejorar sus condiciones generales.

${ }^{5}$ Campello, "Entregue á municipalidade o plano definitivo de reforma do bairro de Santo Antônio. As solenidades de hontem no Teatro Santa Isabel. Os discursos do interventor federal, prefeito da capital e jornalista José Campello", Folha da Manbã, Recife, 24 de abril de 1938 , p. 3 . de este problema. Se podría decir que de ellos provienen todas las miserias morales y materiales y todos los vicios. En los barrios bajos hay tuberculosis y alcoholismo. Se desarrollan en ellos bajos instintos. Luchar contra los barrios pobres es tomar parte en una batalla para elevar la moral y mejorar la salud física de la raza. Este medio está usualmente ocupado por la clase trabajadora, la clase que precisamente necesita más higiene moral y física. En este medio repulsivo, el trabajador forma su familia y establece su casa. Si esta casa está en esa condición, nada es más de desear que escapar para olvidar y buscar distracción en el bar; va a éste cada vez más, entregándose a vicios como el juego y la bebida. De vuelta a su casa, se encuentra con un hogar repulsivo que lo hace pensar con frecuencia que está excluido de la sociedad. A partir de esto lo corroe la envidia y el odio crece contra aquellos a quienes cree responsables de su miseria. Este ambiente tiene consecuencias desastrosas en la niñez. Los niños viven sin distinción de sexo y adoptan los peores comportamientos, los cuales llevan a la escuela y al lugar de trabajo. Se vuelven vagabundos, porque prefieren la calle en donde pueden respirar y pasan la mayor parte del tiempo ahí en vez de en su habitación repulsiva. Las niñas en este ambiente pierden toda noción de honor y dignidad. En suma, los barrios bajos son las causas directas de la falta de organización de la clase trabajadora; son un obstáculo absoluto a la elevación física y moral de la clase trabajadora. Deben ser demolidos. ${ }^{6}$

Esta visión de los problemas urbanos a través de los ojos de dos profesionales profundamente involucrados en la génesis del movimiento urbanista en América del

${ }^{6}$ Mendonça, "Casas", 1931, p. 141. 
Sur, es asombroso por el prejuicio y el temor a la multitud. Este ensayo explora la génesis de un discurso sobre urbanismo, colocándolo en el corazón del paisaje cultural contemporáneo. Para hacerlo, se exploran una vista general del crecimiento urbano, los cambios en la ciudad y la coyuntura intelectual del periodo.

\section{EL CRECIMIENTO DE LAS CIUDADES}

Desde el siglo XIX, las ciudades de América del Sur experimentaron un enorme crecimiento demográfico. Río de Janeiro duplicó su población en 16 años, con un crecimiento de más de un cuarto de millón de habitantes entre 1890 y 1906. Buenos Aires experimentó el mismo proceso, su población se duplicó, sobrepasando el medio millón de habitantes (543 360). São Paulo presenció un proceso similar. Su población se elevó casi cuatro y media veces en 17 años, entre 1890-1907. Eso significó un incremento de casi un cuarto de millón de individuos habitando su territorio, laborando en su economía, viviendo en sus casas y produciendo su riqueza con parte de ellos sujetos a pobreza.

Recife en Brasil y Rosario en Argentina, ciudades menos importantes que las mencionadas más arriba, también tuvieron un innegable crecimiento demográfico. Ciudades de tamaño similar, ambas con alrededor de 100000 habitantes al principio del siglo, experimentaron curvas demográficas comparables, al menos entre 1900 y 1920. Recife duplicó su población en ese periodo, cuando rebasó los 200000 habitantes. Rosario duplicó su población en diez años (1900-1910). Cuando Recife alcanzó los 233000 habitantes en 1920 , la población de Rosario seguía siendo mayor, con un cuarto de millón de habitantes. Aun con una reducción de su tasa de crecimiento de $100 \%$ entre 1900 y 1910 , a $25 \%$ en la siguiente década, ello significó un crecimiento considerable.

Si se continúa comparando las tres metrópolis -Río de Janeiro, São Paulo y Buenos Aires-después de 1906, la tasa de crecimiento demográfico sigue siendo alta. Entre 1906 y 1920, Río, con un crecimiento menor que Buenos Aires, tuvo un incremento de $42.5 \%$. La población de Buenos Aires, ligeramente más pequeña que la de Río en 1890 , la rebasó en $20 \%$ en 1906 , con un total de más de un millón de habitantes, y ha permanecido más grande que la de Río desde entonces. En 1920, la llamada "París de América del Sur" tuvo un crecimiento de población de más de medio millón. Eso significaba que casi 700000 habitantes adicionales vivían en Buenos Aires, tres veces el tamaño de la segunda ciudad argentina del periodo -Rosario. A partir de entonces, Río sufrió un crecimiento poblacional de $65 \%$ entre 1920 y 1928 , incorporando más de tres cuartos de millón de individuos en su espacio. Esto significó que en sólo ocho años absorbió un número de habitantes casi equivalente a la población de la segunda ciudad de Brasil más grande de ese tiempo, São Paulo, ella misma ya no una ciudad pequeña, con una población de más de 800000 . Entre 1905 y 1930 , São Paulo triplicó su población, añadiendo más de medio millón de habitantes y creciendo de 279000 a 822 400. En el mismo periodo, la capital de Argentina, que crecía menos rápidamente que esas dos ciudades brasileñas, duplicó de nuevo su población, añadiendo casi 1200000 habitantes. 


\section{SECUENCIG}
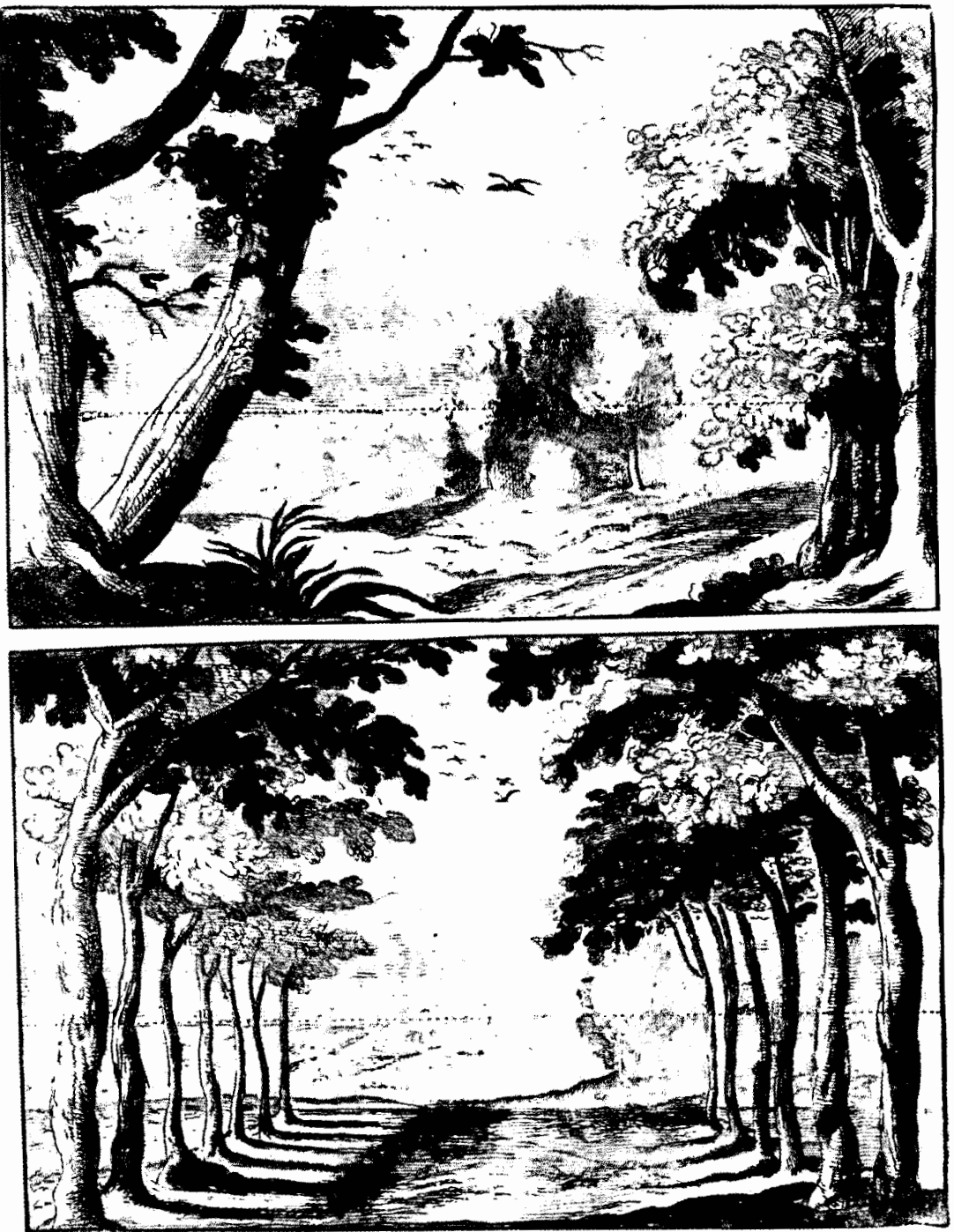


\section{SECUENCIE}

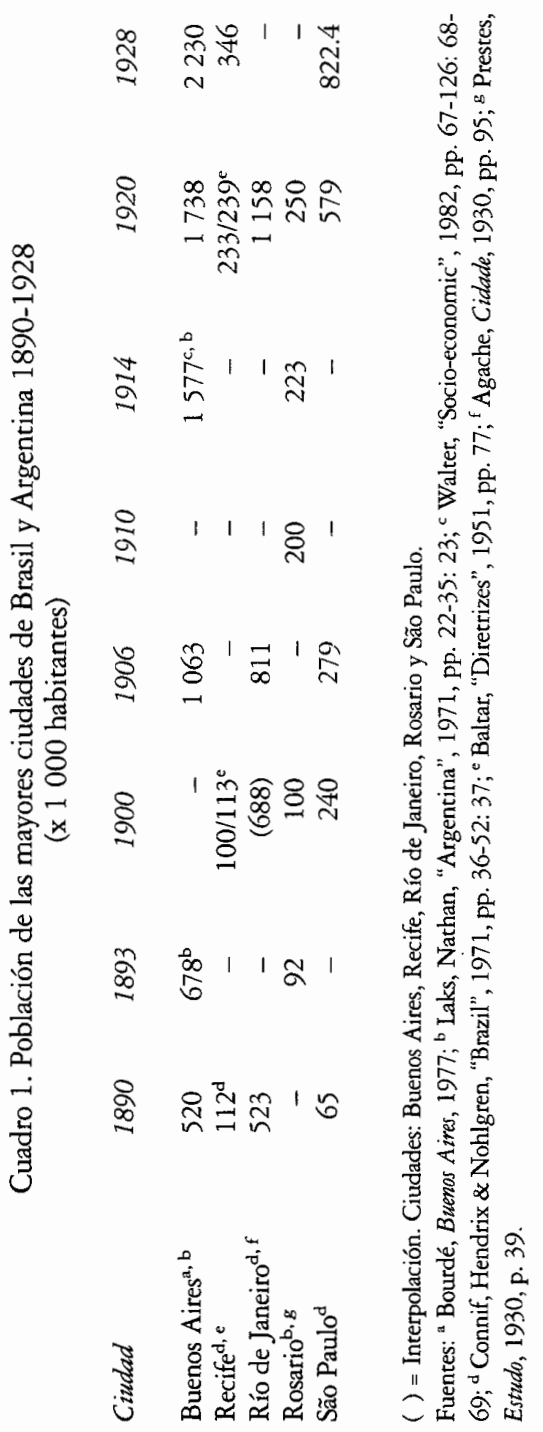




\section{LA RENOVACIÓN DE LOS DISTRITOS CENTRALES}

La enorme experiencia de crecimiento demográfico experimentada en América del Sur creó una sobrecarga de servicios. El centro de la ciudad, un lugar en donde se hallaban la industria y el comercio, y consecuentemente los trabajos, recibió una parte significativa de este incremento de población. La densificación del corazón urbano se originó principalmente del deseo de la población de vivir en el centro, cerca de los lugares de trabajo. ${ }^{7}$ Tal concentración de la población creó un deterioro de la disponibilidad de alojamiento y de las condiciones urbanas en su totalidad. Las fracciones desempleadas y más desposeídas de la clase trabajadora encontraron dos maneras de obtener una habitación. Primero, estaban los cortiços o casas de cômodos en Brasil o los conventillos en Argentina, un tipo de habitación que consiste en antiguas casas de clase media con muchas habitaciones atestadas. Una siguiente y posible variación del cortiço fueron varias casas reunidas en cuadrángulo y construidas en el mismo lote. La segunda alternativa comprendió los mocambos (chozas) y las favelas (construcciones de barrio pobre), casas construidas por los mismos habitantes, efímeras, insalubres, hechas de materiales naturales como arena, hojas de palma, con pedazos de materiales tradicionales como tabiques y tejas o una mezcla de todo esto. Estas casas se construyeron en parcelas no pertenecientes a los mismos habitantes, y a menudo en sitios en donde era difícil introducir

\footnotetext{
${ }^{7}$ Sargent, Spatial, 1974, p. 29.
}

servicios urbanos e infraestructura, por ejemplo, en colinas y ciénagas. ${ }^{8}$

Cuando la economía alcanzó cierto grado de desarrollo, surgió el problema de la circulación. La estructura urbana se convirtió en un obstáculo para el desarrollo económico. En América del Sur, para reducir la circulación de gente y servicios en el sistema de transporte y también por razones de salud pública, el Estado intervino en las ciudades. Esta intervención estuvo caracterizada por la renovación de distritos centrales en las ciudades grandes. En Río hubo una famosa renovación del centro de la ciudad, emprendida durante la administración del ingeniero Pereira Passos (un Haussmann tropical, según el diplomático Barão do Rio Branco) "y durante su función de alcalde (19021906).$^{10}$ Esta renovación se caracterizó por la demolición de la Colina del Senado así como de muchas construcciones, inclusive cortiços, que eran esenciales para la apertura de avenidas. ${ }^{11}$ Esto fue acompañado de grandes trabajos de saneamiento llevados a cabo bajo la dirección del higienista Oswaldo Cruz, lo que resultó en una significativa reducción de la mortalidad debida a enfermedades contagiosas en al-

\footnotetext{
${ }^{8}$ Para una descripción de las favelas y mocambos véase Marianno Filho, "Technica", 1939.

9 Benchimol, "Pereira", 1982.

${ }^{10}$ La renovación se basaba en un plan propuesto por un comité en los años 1870 , en el que Passos era miembro. Para los reportes de este comité véase Commissão, Primeiro, 1875, y Commissão, Segundo, 1876. Los dos reportes provocaron un debate con el ingeniero Vieira Souto. Para sus comentarios véase Souto, Melhoramentos, 1875; Melboramentos, 1876. Para un estudio del plan en el contexto del periodo en que fue propuesto véase Gantos, "Progresso", 1993.

${ }^{1.1}$ Abreu, Evolução, 1988, p. 63.
} 
gunos grupos sociales, en especial la fiebre amarilla entre la población europea. ${ }^{12}$

La evidencia de que la circulación era fundamental durante ese periodo es el hecho de que el puerto fue también reformado y ampliado, los distritos sureños como Copacabana y Jardim Botanico se ligaron al centro con la construcción del Túnel Leme, inaugurado en 1906, y hubo cambios tecnológicos en el sistema del transporte público con el reemplazo de animales por energía eléctrica con la electrificación de muchas compañías de tranvías, como la Companhia Jardim Botanico en 1904 y las compañías São Cristovão, Carris Urbanos y Villa Isabel en 1905 . Estas tres compañías se unieron bajo la empresa canadiense que tenía la concesión del abasto de electricidad a la ciudad, la Rio de Janeiro Tramways, Light and Power Company Limited. ${ }^{13}$

São Paulo también tuvo obras públicas. Durante la administración del alcalde Antonio Prado (1899-1911) se abrió la avenida Angélica, entre otras, y se mejoró tecnológicamente el sistema de transporte, que fue electrificado. Durante la administración de Raimundo Duprat (19111914) se ampliaron otras calles, como la Libero Badaró y Boa Vista, así como plazas como Praça da Sé y Praça de São Fran-

${ }^{12}$ Bodstein, "Prácticas", 1986. Otros artículos referentes a la reforma durante el periodo de Passos incluyen Barbosa, "Modernização", 1990; Carvalho, "Urban", 1984, y "Search", 1988; Kessel, "Crescimento", 1983; Needell, "Rio de Janeiro", 1983; Tropical, 1987; "Rio de Janeiro", 1995; Meade, Civilizing, 1997; Pechmann, "Reformas", 1983; Pechmann y Fritsch, "Reforma", 1985; Pereira, "Reforma", 1992.

${ }^{13}$ Abreu, Evolução, 1988, pp. 63, 66-67. Para un estudio sobre la compañía véase McDowall, Light, 1988. cisco. En ese tiempo se construyó el paso a desnivel Santa Efigênia, junto con la ampliación de la avenida São João para permitir la construcción de un anillo periférico. ${ }^{14}$ Estas mejoras eran parte de proyectos parciales propuestos junto con un debate sobre la organización del centro de la ciudad que tuvo lugar entre 1906 y 1911 en São Paulo. El punto de partida de esta discusión fue la construcción del Teatro Municipal (1903-1911), un edificio ecléctico diseñado por el arquitecto Ramos de Azevedo y un símbolo de la modernidad europea implantada por la elite gubernamental. La construcción del teatro junto al valle Anhangabahú, en donde un arroyo contaminado recibía las aguas negras de un matadero, pero en donde había todavía rasgos rurales como plantaciones de vegetales y de té, originó una serie de propuestas para el embellecimiento de la calle y su paisaje. ${ }^{15} \mathrm{La}$ primera de estas propuestas fue presentada al Consejo de la Ciudad por el ex director de Obras Públicas de Río, Augusto Carlos da Silva Telles, quien se convirtió en concejal de la ciudad en São Paulo. La propuesta estaba caracterizada por preocupaciones estéticas y el deseo de resolver los problemas de circulación relacionados con la estrechez de la calle Libero Bardaró, y fue enviada para análisis por el comité de obras, justicia y finanzas del Consejo. ${ }^{16}$

A pesar del apoyo de otros concejales, la propuesta había estado olvidada por año y medio cuando fue readoptada por Silva Telles en 1908, presentada como ley y estudiada por los ingenieros Víctor da Silva Freire y Eugênio Guillem, di-

\footnotetext{
${ }^{14}$ Osello, "Planejamento", 1983, p. 82.

${ }^{15}$ Simões, "Setor", 1990, pp. 79-80.

${ }^{16}$ Ibid., pp. 80-83.
} 
rector y vicedirector de la Direcção de Obras Municipaes respectivamente. ${ }^{17} \mathrm{El}$ proyecto recibió enmiendas en las comisiones del Consejo y se convirtió en ley, ahí las ideas de Telles fueron simplificadas por razones financieras a causa de expropiaciones e intereses privados, perdiendo sus ideales estéticos y convirtiéndose meramente en una respuesta a problemas de tránsito. ${ }^{18}$ Con la aprobación de la ley, el Consejo negoció con el gobierno del estado para obtener apoyo para las mejoras y para ser incluido en el presupuesto de 1911. ${ }^{19} \mathrm{Al}$ mismo tiempo, el gobierno provincial promovió otro proyecto para el centro de la ciudad diseñado por el arquitecto Samuel Augusto das Neves, de la Secretaria de Agricultura, Commercio y Obras Públicas, que fue publicado en el diario Correio Paulistano. Este proyecto respondía a los intereses de los propietarios de la región y fue probablemente diseñado de acuerdo con ellos, permitiendo la reconstrucción de sus edificios en la calle Libero Badaró a cambio de la donación de tierra para su extensión y alineamiento con otras calles. ${ }^{20}$

El proyecto de Neves proponía un extenso boulevard tipo Haussmann en el valle Anhangabahú, en oposición a las ideas presentadas por Víctor da Silva Freire y Eugênio Guillem, que estaban próximas a las ideas de Camilo Sitte (18431903) en su libro Der Städtebau nach seinen kiinstlerischen Grundsätzen, que valoraba la conservación del diseño espontáneo existente en vez de bulevares rectos. Más

${ }^{17}$ Ibid., pp. 84-86.

${ }^{18}$ Ley 1.3331 del 6 de junio de 1910 , véase ibid., pp. 88-93.

${ }^{19}$ Ibid., p. 92.

${ }^{20}$ Ibid, pp. 98-99. que sólo una confrontación entre las administraciones del estado y la municipal, las dos propuestas llevaron a un debate que tuvo como su momento más importante la conferencia dada por el ingeniero Víctor da Silva Freire en la Escola Polytechnica por invitación de su sociedad de estudiantes. Publicada en la Revista Polytechnica, la publicación técnica y científica de la sociedad de estudiantes, la conferencia está considerada uno de los textos fundadores del urbanismo en Brasil, al menos en São Paulo. ${ }^{21}$

Notable por su referencia a los desarrollos en urbanismo a un nivel internacional -incluyendo la enseñanza- esta conferencia mencionó a urbanistas extranjeros como Charles Bull, Baumeister, Hénard, Charles Mulford Robinson y, por último, Camilo Sitte, su principal fuente de inspiración. En esa ocasión, Víctor da Silva Freire utilizó la experiencia extranjera para señalar un punto importante: en vez de la adopción de proyectos parciales como los que se discutían, se necesitaba plantear un plano geral (plano general) para toda la ciudad. ${ }^{22}$ Unos pocos meses después de la conferencia de Freire, el alcalde contrató al arquitecto de paisajes Joseph Antoine André Bouvard para que analizara los proyectos en competencia. En su reporte, Bouvard propuso una solución conciliatoria, aportando ideas contenidas en ambas propuestas y compartiendo la ejecución de su proyecto entre los autores de los esquemas previos. El proyecto urbano iba a ser ejecutado por ingenieros municipales, mientras que los edificios serían diseñados por la oficina arquitectónica de Samuel das Neves. Estas

\footnotetext{
${ }^{21}$ Freire, "Melhoramentos", 1911.

${ }^{22}$ Ibid., pp. 101 y 1.10.
} 
propuestas fueron finalmente realizadas en el centro de la ciudad de São Paulo durante el periodo en que Raimundo Duprat era alcalde. ${ }^{23}$

Recife también encaró un proceso similar. Uno de los distritos centrales de la ciudad fue renovado, con la mejora de sus condiciones de tránsito, por la reforma de su puerto entre 1909 y 1913 . Este proyecto también fue realizado por razones de salud. De hecho, el proyecto de drenaje $\mathrm{y}$ agua potable fue propuesto por el ingeniero sanitario Francisco Saturnino de Brito, y fue ejecutado entre 1909 y $1917 .{ }^{24}$ El periodo fue también de cambios significativos en la circulación urbana. Las compañías de tranvías como la Recife Street Car Company, que originalmente usaban tracción animal, se electrificaron en 1914, un poco después que las otras ciudades mayores, cuando la concesión para este servicio fue otorgada a la Pernambuco Tramways, Light and Power Limited, una compañía propiedad de accionistas ingleses, que había adquirido la concesión para proporcionar electricidad a la ciudad. 25

Al otro lado del río Paraná, en Argentina, se llevaron a cabo desarrollos semejantes en la ciudad capital. Más temprano que en las ciudades brasileñas, y tras la aprobación de un proyecto por el consejo de la ciudad en 1889 durante la admi-

${ }^{23}$ Osello, "Planejamento", 1983, pp. 60-63; Simões, "Setor", 1990, pp. 115-126.

${ }^{24}$ Para la renovación del puerto y el distrito véase Lubambo, Corpo, 1988. Para el proyecto sanitario véase Brito, Saneamento, 1917.

${ }^{25}$ Para la historia de los tranvías de tracción animal y su influencia en el desarrollo de la ciudad y viceversa véase Zaidan, "Recife", 1991. Para datos sobre los tranvías eléctricos véase Mota, Tempo, 1985. nistración del alcalde Torcuato de Alvear (1880-1887), se llevó a cabo la apertura de la avenida de Mayo, ${ }^{26}$ ligando la plaza de Mayo, en donde se encuentra la Casa Rosada, el palacio presidencial, a la plaza Lorea, en donde fue construido el edificio del Parlamento Nacional, que se inauguró en 1906 (antes estaba situado en la plaza de Mayo). ${ }^{27} \mathrm{La}$ avenida de Mayo fue inaugurada en 1894 y terminada en 1896. Buenos Aires tenía un proyecto diseñado también por Bouvard. ${ }^{28}$ En 1906, antes de su viaje a São Paulo, Bouvard había sido contratado para hacerlo cuando se nombró un comité para que trabajara con él..$^{29}$ El diseñador francés también diseñó un plan para Rosario. ${ }^{30}$

Como en São Paulo unos años después, el proyecto de Bouvard para Buenos Aires reconcilió estudios previos propuestos por profesionales locales. A principio del siglo XX tuvo lugar un debate relacionado con la celebración del centenario de la independencia de Argentina, que consideraba la transformación física de la capital. Por una parte estaban los defensores de avenidas perpendiculares que seguían un diseño de malla de acero, característico de la colonización hispano-

${ }^{26}$ Bragos, "Urbanismo", 1991, p. 8; Hardoy, "Evolución", 1955, p. 105.

${ }^{27}$ Scobie, Buenos Aires, 1974, pp. 109-113.

${ }^{28}$ Hardoy, "Evolución", 1955, p. 100.

29 Esta comisión estaba formada por el arquitecto francés de paisaje Carlos Thays, director del Servicio de Parques y Paseos de Buenos Aires; del ingeniero Carlos María Morales; del concejal de la ciudad Fernando Pérez, miembro de la Comisión de Avenidas y del director de la Comisión Nacional de Obras Públicas, Higiene y Seguridad Social, el ingeniero Anastasio Iturbe, véase Novick, "Técnicos", 1990 , p. 5.

${ }^{30}$ San Vicente, "Planes", 1986. 
americana, que ya existía en la ciudad. Por la otra estaban los defensores de avenidas diagonales como solución para los problemas de circulación. Este debate tuvo lugar en el Parlamento Nacional en 1905. El proyecto de avenidas perpendiculares fue defendido por los diputados Eugenio Badaró y Canton, mientras que el proyecto de vías ortogonales fue apoyado por tres diputados-Miguel Desplats (autor de una obra de mejora urbana en 1906), ${ }^{31}$ Varela y Pérez. ${ }^{32}$

Durante el debate se presentaron otras propuestas. Un tercer proyecto fue diseñado en 1906 por el arquitecto Henrique Chanourdie, director de Arquitectura, la revista de la Sociedad Central de Arquitectos. ${ }^{33}$ Éstas eran las ideas de urbanismo cuando Carlos Torcuato Alvear, alcalde de Buenos Aires (1907-1909), invitó a Bouvard a diseñar un proyecto para la ciudad. El debate del Parlamento terminó en 1912, con la promulgación de leyes de expropiación para abrir dos avenidas diagonales partiendo de la plaza de mayo, así como también una extensa avenida norte-sur. Un año antes, un código de construcción había sido aprobado con el control de las fachadas como su objetivo principal. ${ }^{34}$ A pesar de su diversidad y riqueza, todos estos proyectos propuestos en ambos países se caracterizaron por un enfoque parcial y fragmentario del urbanismo, nunca tomando en cuenta la totalidad del territorio urbano como unidad para la intervención.

${ }^{31}$ Desplat, Mejoras, 1906.

32 Novick, "Técricos", 1990, p. 4.

${ }^{33}$ Chanourdie, "Transformación", 1906-1907.

${ }^{34}$ Las leyes para abrir avenidas tuvieron los números 8.854 y 8.855 , véase Novick, "Técnicos", 1990 , pp. 4-5.

\section{LA GÉNESIS DEL URBANISMO}

Durante las dos primeras décadas del siglo $\mathrm{xx}$ la idea de urbanismo, definido como un proyecto que toma en cuenta la ciudad entera para la intervención, se estableció tanto en Brasil como en Argentina. En Argentina, en 1906, el arquitecto Christophersen proclamó la necesidad de elaborar un plan para Buenos Aires, y en Brasil, el ingeniero y arquitecto Víctor da Silva Freire, cuando fue invitado por estudiantes de la Escola Polytechnica para dar una conferencia en 1911 sobre dos proyectos parciales en competencia para el centro de São Paulo, habló sobre esa misma necesidad. En 1917 Saturnino de Brito, un ingeniero sanitario dedicado a la planeación y construcción de los sistemas de agua potable y drenaje de Recife, hizo eco a la misma idea.

En ambos países, los años 1920 señalaron el nacimiento de los primeros planes modernos propuestos para sus ciudades. En 1923 se creó un comité en Buenos Aires, la Comisión de Estética Edilicia, encargada de proponer un plan de la ciudad, y en Río de Janeiro, Alfred Agache, un urbanista francés, fue designado para el mismo propósito cuatro años después. ${ }^{35}$ El Parlamento estatal de Pernambuco votó el mismo año una ley autorizando al gobernador para emplear a Agache en el diseño de un plan para la capital, Recife. ${ }^{36}$ En 1929 el ingeniero Prestes Maia trabajaba también en el llamado Plan de Avenidas para São Paulo. ${ }^{37}$ Estas ciuda-

${ }^{35}$ Agache, Cidade, 1930

${ }^{36}$ Outtes, Recife, 1997, pp. 67-70.

${ }^{37}$ Maia, Estudo, 1930. Maia discutió la aplicación de su plan durante sus funciones como alcalde (19381945) en Maia, "Remodelação", 1941; Melboramentos, 
des, a pesar de sus diferencias de población, tenían la misma preocupación en el mismo periodo: planear su crecimiento y controlar su expansión. Esta nueva actitud demostró ser un punto clave en el paradigma de pensar en o intervenir las ciudades. No era ya únicamente cuestión de abrir nuevas avenidas para mejorar la circulación del tráfico o renovar el centro de la ciudad infestado por caseríos pobres, como fue en casos anteriores.

Dentro de los 23 años que separaban las afirmaciones de Christophersen y la publicación del plan de Agache, nació el urbanismo en Brasil y en Argentina, cambiando la práctica en este campo en sólo unos cuantos años. Nuevos procedimientos se crearon en esta práctica. Reunir un conocimiento detallado de las condiciones urbanas antes de planear se volvió una nueva preocupación, de la que se originaron estudios de crecimiento demográfico, salud pública y epidemias pasadas, sistemas de transporte, el presupuesto municipal y la historia de la vida de la ciudad. Se propusieron nuevas instituciones para monitorear y garantizar la aplicación de los planes. Luego de ser aprobados, éstos resultaron siempre en una ley que establecía códigos de construcción más complejos y restrictivos.

La aplicación de los planes y la institucionalización del urbanismo como disciplina autónoma, tuvieron lugar, en ambos países, bajo regímenes políticos intervencionistas y antiliberales, como los años de Vargas en Brasil (1930-1945), especialmente la dictadura del Estado Novo (Esta-

1945. La creciente literatura sobre Maia incluye Anonymous, "Pintor", 1996; Campos, "São Paulo", 1996; Nunes, "Prestes", 1996; Pontes, "Francisco", 1996; Toledo, Prester, 1996, y Zmitrowicz, "Sonho", 1996. do Nuevo) (1937-1945), y en Argentina bajo los gobiernos militares del general José F. Uiriburu (1930-1932) y los presidentes Agustín P. Justo (1932-1938), Roberto M. Ortiz (1938-1940) y Ramón S. Castillo (1940-1942). ${ }^{38}$ Bajo estos gobiernos se implantaron algunas de las propuestas de Agache para Río de Janeiro, y el Plano de Avenidas en São Paulo fue llevado a cabo, así como parte de las propuestas contenidas en el plan de Néstor de Figueiredo para Recife. En Buenos Aires, la Oficina del Plan de Urbanización se creó en 1932, seguida de un plan propuesto en 1935 por el urbanista alemán Werner Hegemann y los argentinos Kalnay y Carlos María della Paolera.

Por una parte, había una nueva práctica relacionada con la administración urbana. Por la otra, estaba el nacimiento de un nuevo tipo de conocimiento: el urbanismo, o lo que se llamaba "la ciencia de planificación de ciudades". Esta "nueva ciencia" implicaba la creación de nuevos productores de este conocimiento, nuevos intelectuales y profesionales, los urbanistas. Tal conocimiento fue institucionalizado, convirtiéndose en profesión autónoma con la enseñanza del urbanismo en las universidades. En 1919 se creó el primer profesorado de urbanismo en Argentina, en la Facultad de Ciencias Físicas y Naturales de la Universidad de Rosario, cuando della Paolera fue nombrado para el cargo. En Brasil se instituyeron conferencias sobre urbanismo en São Paulo, en 1923, en el Mackenzie College, y en 1926 en la Escola Polytechnica; ${ }^{39}$ en Río de Janeiro en la Universidade do Distrito Fe-

\footnotetext{
${ }^{38}$ Scobie, Argentina, 1971 , pp. 260-261.

39 Ficher, "Ensino", 1989, vol. 1, p. 230.
} 
deral en 1935, y en Recife en la Escola de Belas Artes al año siguiente.

La propuesta de planes para toda la ciudad, señalando una dimensión espacial para resolver problemas urbanos, fue seguida por una nueva exposición razonada. Esta incluía rasgos como el taylorismo, el racionalismo técnico y la recreación de la ciudad como espejo de la fábrica, reflejando su lógica funcional, aun cuando estos países tenían una economía agrícola más que industrial; la mayoría de la población vivía en áreas rurales, a pesar de la concentración de la población en Buenos Aires. De los años 1920 a los 1940 hubo un cambio en las representaciones de la ciudad. Siguiendo la exposición de los urbanistas, el racionalismo técnico y la lógica científica debían regular las actitudes y el comportamiento de la sociedad en la ciudad. La ingeniería, una profesión técnica par excellence, adquirió puestos importantes en la administración municipal. Un número significativo de los alcaldes en las ciudades brasileñas más importantes tenían títulos de ingeniero durante los años 1930-1945. La hegemonía de la tecnociencia dio por resultado la idea de que el urbanismo era científico, y según los urbanistas, se consideraba de interés general para toda la sociedad. El discurso de los ingenieros y los urbanistas incluyó la idea de que las instituciones representativas, típicas de las sociedades democráticas, no eran eficientes. Desde su punto de vista, la política estaba en oposición con las necesidades de la ciudad moderna. Este autoritarismo se volvió realidad, al menos en el nivel municipal, bajo los gobiernos intervencionistas y antiliberales de los años 1930 y 1940.

El movimiento para la reforma habitacional urbana era parte de uno más gran- de: el movimiento por la reforma social. En este sentido los urbanistas, médicos, ingenieros, abogados, alcaldes y activistas en el movimiento de vivienda deben ser vistos como reformistas sociales. Previo a la institucionalización de la planificación de ciudades y de la adopción de políticas de vivienda por el Estado, estos reformistas sociales frecuentaban organizaciones como las asociaciones de profesionistas, entidades filantrópicas, sociedades de beneficencia, ligas antialcohólicas, clubes de ingenieros, institutos de arquitectos y federaciones médicas. En estos espacios apareció la reforma ideal, fue debatida y desarrollada. El lenguaje del discurso del nuevo conocimiento se forjó en estas instituciones, en donde las competencias profesionales eran también legitimadas.

El discurso de los urbanistas en este periodo incluía un proyecto para disciplinar a la sociedad por medio de la ciudad. Este proyecto fue investido con las icleas en boga en el paisaje cultural del periodo, como positivismo, higiene social y eugenesia. Como el ánimo que prevalecía era modificar el comportamiento cotidiano y las actitudes de la población mediante la inducción de ciertas reglas y patrones, puede verse como una práctica disciplinaria similar, en algunos aspectos, al encarcelamiento, como lo analiza Foucault. ${ }^{40}$

\section{REPRESENTACIONES URBANAS}

El discurso de los urbanistas produjo un retrato de la ciudad, la sociedad y el poder político. Una línea coherente de pensamiento se construyó en la mente de los

$$
{ }^{40} \text { Foucault, Surveiller, } 1975 .
$$



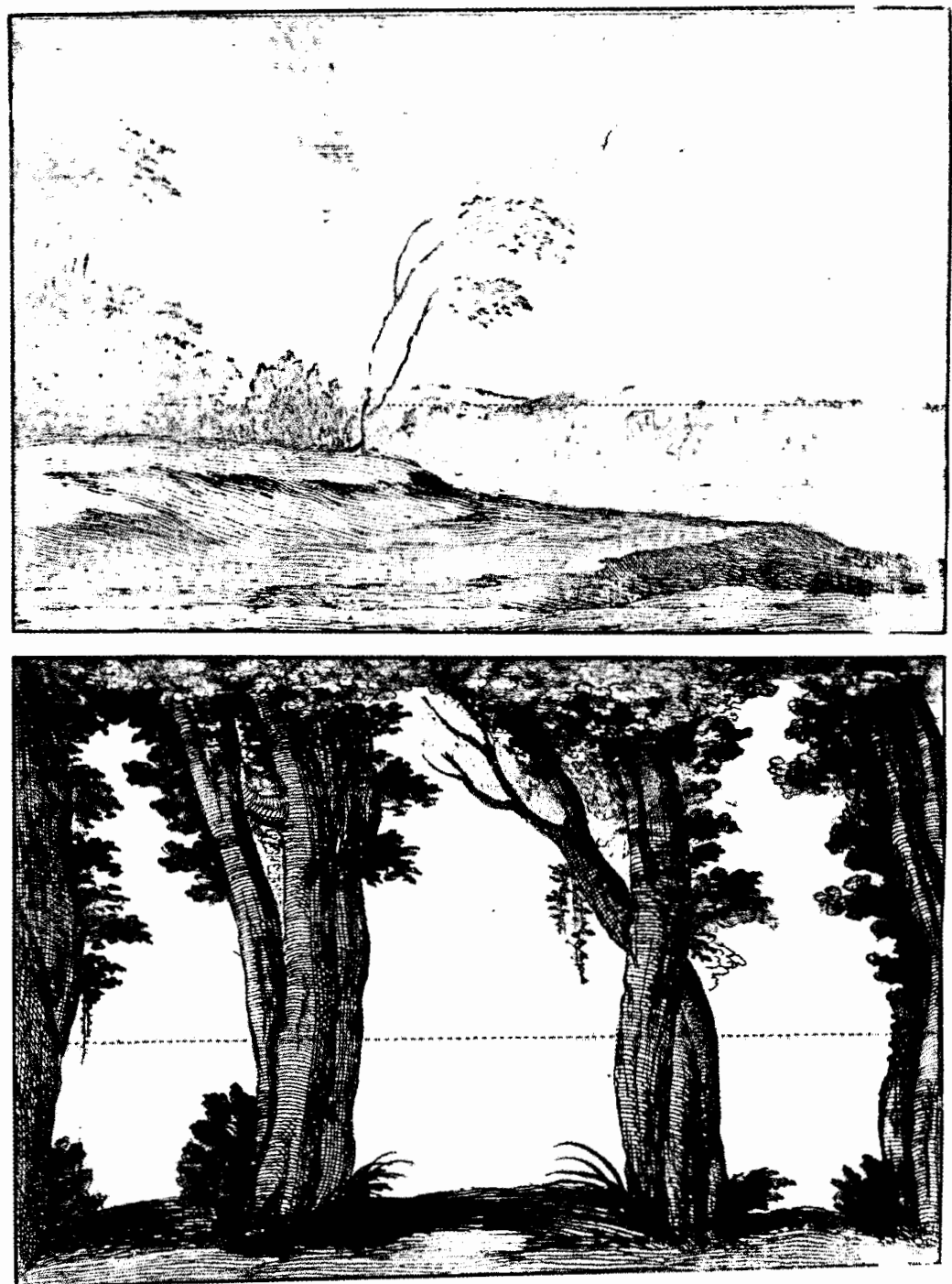
profesionales, quienes inventaron una cuestión social que levantó y construyó en las ciudades una representación de la vida diaria llamada "problemas urbanos". $\mathrm{Al}$ igual que todas las líneas, ésta era un conjunto de puntos muy próximamente ligados para hacerlos visibles. El punto de partida era la vivienda. Bajo el punto de vista de los urbanistas, la habitación en la que los pobres y hasta la clase trabajadora vivía era sucia y peligrosa. Si la casa era considerada insalubre, indeseable, inapropiada, ¿cómo veían aquellos que la consideraban así al conjunto, a la ciudad? Aquellos que veían la habitación insalubre, ¿veían la ciudad saludable, limpia, hermosa? La imagen de la ciudad que dan es dual: una a colores, la otra negro y blanco, ambas reveladas en el mismo papel fotográfico añejo, ajado y sucio. Por una parte, la exuberancia de la naturaleza -su luz y las tonalidades del arco irisaparece en las fotografías a color:

Las ciudades brasileñas, con sus divertidas avenidas, sus expresivas montañas, sus playas seductoras, sus palacios pintorescos, su cielo claro y azul, tienen algo de magnético, fascinante y absorbente que embriaga y encanta cuando uno las ve por primera vez. ${ }^{41}$

Esta no es toda la imagen de la ciudad. Se apaga la luz, los colores se desvanecen, y aun el magnetismo, la fascinación, el encanto y los placeres de embriaguez se transforman en repulsión, distancia y depresión cuando el mismo fotógrafo voltea la hoja del mismo papel fotográfico para mostrar una imagen en blanco y negro:

${ }^{41}$ Oliveira, "Casa proletaria", 1940, p. 187.
Desventuradamente, hay también, como en otras ciudades de otros países, la otra cara de la moneda, lo opuesto a la belleza, la sombra de la magnífica pintura. En las ciudades brasileñas hay también, como en las ciudades de otros países, conjuntos de barrios pobres, áreas infortunadas con todo tipo de habitaciones miserables. ${ }^{42}$

Con muchas fotografías como ésta se construye un panorama, estableciendo una liga, una secuencia y una coherencia entre cada una. Esta liga es el efecto determinante del medio ambiente sobre el hombre, la familia y la sociedad. Se pensaba que el medio ambiente influye en el hombre y determina su comportamiento, pero ese mismo medio ambiente puede ser transformado por el hombre, cambiando las precondiciones de su influencia. Tal reflexión se encuentra en las mentalidades de los urbanistas sudamericanos:

La principal finalidad de la planificación de ciudades es alojamientos salubres, sitios de trabajo higiénicos, casas ventiladas y con gusto estético para la felicidad del hombre. El poder público debe procurar amplios espacios libres, para la práctica de deportes, jardinería y el descanso de los pobres, porque ha sido probado por las estadísticas que donde existen parques, albercas, plazas, sitios de juego, la salud y la higiene se mejoran de tal manera que la moral se cambia y disminuye la delincuencia juvenil de manera notable. ${ }^{43}$

\footnotetext{
${ }^{42} \mathrm{Ibid}$.

${ }^{43}$ Prado, "Urbanismo", 1941, p. 42. Para otra declaración de contenido muy similar ver Estelita, "Parques", 1935, y Mello, 1929, pp. 150 y 153.
} 


\section{REFORMA SOCIAL}

A despecho de determinar un comportamiento físico y moral, el medio ambiente puede ser cambiado en él mismo, transformado y reformado; si la decadencia aparece, hay al menos la esperanza de la mejoría, y esta mejoría puede ocurrir justo por un cambio en las condiciones de vida de la gente, la reeducación de los pobres y la reforma social. Esta solución a la cuestión social fue propuesta a ambos lados de los ríos Plata y Paraná. El diputado Juan Cafferata, delegado de la municipalidad de Córdoba (Argentina) del Primer Congreso Latinoamericano de la Vivienda Popular, lo dijo claramente en el discurso de inauguración en 1939:

Bienvenidos a esta asamblea de paz y fraternidad, que nos ha reunido en el esfuerzo común de buscar la justicia social, con la intención de una mejoría de vida por medio del trabajo que proporciona dignidad, por un salario justo, y por una vivienda que sea adecuada a la familia humana. ${ }^{44}$

La cuestión social es un conjunto compuesto de diversos elementos: vivienda, salud, vicio, alcoholismo, drogadicción, enfermedad mental y criminalidad; en suma, la cuestión social es un complejo de problemas sociales. Refiriéndose a los urbanistas, los problemas sociales a los que tenían que dar repuesta eran la vivienda social y especialmente la ciudad. A sus ojos, la ciudad era caótica, problemática y degradaba a las generaciones jóvenes. De acuerdo con ellos, la población vivía en viviendas atestadas, las calles en los barrios pobres no eran suficientemente

${ }^{44}$ Cafferata, "Congreso", 1939, p. 163. anchas para permitir a los higiénicos rayos solares brillar y esas condiciones insalubres facilitaban la difusión de epidemias. Todas estas cosas sucedían porque las ciudades crecieron espontáneamente y era necesario planear su desarrollo y controlarlas. El instrumento por el que las ciudades tenían que ser mejoradas se consideraba que era el plan. En Brasil, a partir de 1911, durante la discusión sobre la renovación del centro de la ciudad de São Paulo, la idea ya estaba presente:

un proyecto de esta naturaleza no puede proponerse sin un plan general, y la consideración de sólo una faceta del problema puede llevar a errores potencialmente fatales, arriesgando ser de un costo mayor más adelante. ${ }^{45}$

En Argentina, esta idea apareció más temprano, al menos desde 1906, cuando Alejandro Christophersen, presidente de la Sociedad Central de Arquitectos, expresó sus ideas sobre las obras públicas para la celebración del centenario de la independencia argentina:

El estudio de un plan general para la capital es indudablemente conveniente, colocando las nuevas avenidas, las plazas, parques, paseos y jardines según un diseño lógico, estético y práctico. Con este diseño, podemos empezar el estudio de varios monumentos y edificios, con los que el comité desea celebrar la fecha histórica de $1910 .{ }^{46}$

El concepto totalizante que puede alcanzarse en los planos no puede ser percibido por todos. Para poder apreciarlo, es

\footnotetext{
45 Freire, "Melhoramentos", 1911, p. 110.

${ }^{46}$ Charnourdie, "Transformación", 1906-1.907.
} 
necesario tener una educación profesional, o a lo menos experiencia práctica, para estar preparado para considerar simultáneamente las varias cuestiones que pueden conciliarse para planear la ciudad. Un tipo específico de profesionista puede estar a cargo de la tarea. Tiene que ser un especialista. Este consenso es temporal, ya que una lucha tendrá lugar entre diversos profesionistas para ser el especialista.

\section{LA HIGIENE COMO FUENTE DE INSPIRACIÓN}

La manera en que los higienistas veían la ciudad en el siglo XIX era crucial para la legitimación del urbanismo como una nueva disciplina. El punto de vista de los higienistas sobre el territorio urbano estaba ligado a los descubrimientos desarrollados en las ciencias médicas. Cuando la medicina se volvió medicina social, la ciudad emergió como objeto de interés higiénico. Cuando los médicos se interesaron en el medio ambiente, la medicina se volvió social. La medicina social, preocupada por el medio ambiente, en donde la ciudad es una de las formas posibles, estaba, en su génesis, ligada a una teoría científica específica desarrollada por esos tiempos, la teoría miasmática. Según esta teoría, la causa de las enfermedades y las epidemias era el estado de la atmósfera, la calidad del aire. El aire podría estar envenenado con miasma, sustancias atmosféricas invisibles resultado de la putrefacción de materia orgánica o bien de las emanaciones del cuerpo, como la sudoración. El medio ambiente se convirtió en el corazón mismo de la reforma social, incorporando por lo tanto el problema de la organización espacial en la agenda de reformas. Los barrios pobres y las casas de vecindad, por ejemplo, fueron considerados lugares peligrosos. A causa del hacinamiento y de la proximidad de tanta gente que vivía junta, no había espacio suficiente para la disipación del miasma. Esta condición, desde el punto de vista de los observadores contemporáneos, facilitaba la dispersión de enfermedades físicas y morales.

Esa creencia era fundamental para la génesis de la medicina social. Si el origen de la enfermedad era el aire corrompido por emanaciones putrefactas, debía prestarse atención a la ciudad, el sitio en donde la gente vivía en gran densidad. Previamente la tarea de la medicina era curar, pero a partir de este periodo, cuando se desconfiaba del medio ambiente, inclusive del aire, las prevenciones se volvieron la tarea principal. Evitar la contaminación era en aquel tiempo más importante que curar; en vez de tratamiento, prevención se volvió la palabra clave. Este momento crucial, en donde la medicina se vuelve social, puede identificarse con la génesis de las instituciones encargadas de prácticas especializadas: el control de epidemias, la vacunación y la institucionalización de la profesión médica. ${ }^{47} \mathrm{El}$ nacimiento de la medicina social significa nuevos campos de práctica, los del higienista, una especie de doctor urbano que atestigua la legitimación de una nueva profesión: la suya. Desde el punto de vista de la representación, la ciudad es vista como un lugar de suciedad y enfermedad. A pesar de los cambios en las bases científicas del conocimiento médico alrededor de 1870 , con el reemplazo de la teoría miasmática por la microbiana, correspondiente al desarrollo en la investigación

${ }^{47}$ Foucault, "Nascimento", 1979. 
experimental en bacteriología y microbiología, persistió la representación de la ciudad como un sitio de enfermedades. Un buen ejemplo del poder de esta representación es que en todos los casos de renovación de centros de ciudad a principios de siglo, así como posteriormente en los planes propuestos para las ciudades, se presentó el discurso higiénico.

La fuerza de su representación era tan poderosa que las funciones urbanas se presentaban por medio de una metáfora orgánica. Según esto, la ciudad era vista como un organismo vivo cuyas funciones correspondían a las de la biología animal. Estas ideas se utilizaban, junto a otras, en el plan propuesto por Agache para Río de Janeiro, así como en el propuesto por Correia Lima para Recife. El ingeniero Baptista de Oliveira utilizó también esta metáfora:

El sistema circulatorio de las ciudades está constituido por calles y avenidas, las que obran como arterias y venas. Este sistema trae y distribuye las sustancias necesarias para la vida a todas las partes del cuerpo urbano. El corazón es el centro de la ciudad, al cual convergen todas las corrientes de la circulación. El sistema muscular está representado por la red de líneas eléctricas que contienen la energía necesaria para la industria y su sistema de transporte. Los pulmones de una ciudad son los espacios libres, avenidas, plazas, jardines, parques, campos de juego, etc. De la misma forma que las células extraen oxígeno del cuerpo humano por el contacto con las venas del sistema arterial, las casas reciben el aire y la luz, indispensables para su saneamiento, a través de las aberturas de las ventanas. La red de agua y drenaje son perfectamente comparables a los órganos digestivos. Los grandes merca- dos de alimentos constituyen el estómảgo de la ciudad [...] Al igual que todos los organismos vivos, la ciudad debe obedecer rigurosamente las reglas de higiene, para evitar enfermedades que destruyen y descomponen las células amenazando su existencia. El paralelo entre la ciudad y el organismo puede hacerse constantemente porque cada día se verifica una analogía entre ellos. ¡Salud! La palabra más preciosa de todas, salud, una condición esencial de belleza y felicidad para la aglomeración así como para el ser humano. ${ }^{48}$

Otra indicación del poder de esta idea es que la palabra diagnóstico, de origen etimológico médico, todavía se utiliza para designar la fase de la identificación de problemas en la planeación urbana en Brasil. La ciudad es un organismo enfermo, para el que los médicos urbanos, los urbanistas de la ciudad, pueden dar la receta necesaria para curarla.

\section{LA CIUDAD PRODUCTIVA: \\ TAYLOR COMO MODELO}

Otra teoría desempeñó un papel importante en el paisaje cultural de América del Sur a principios del siglo Xx: el positivismo. ${ }^{49}$ La idea de que la ciencia puede gobernar la actividad humana y la hegemonía de la razón en decisiones concernientes a la sociedad estaba muy vigente en el debate sobre la planeación de las ciudades. El médico Américo Pereira da

48 Oliveira, "Casa popular", 1940, p. 213.

49 Para un estudio de este asunto en Brasil véase Nachman, "Positivism", 1977. Para Argentina: Biagini, Movimiento, 1985. Para un enfoque comparativo: Hale, "Political", 1988. 
Silva, por ejemplo, criticó al gobierno durante el Primeiro Congresso de Habitação (Primer Congreso de Vivienda) en São Paulo, acusándolo de: "ser siempre tímido en la comprensión de que lo que la ciencia ha establecido como fundamental es absolutamente necesario". 50

El ingeniero Armando Godoy adoptó un punto de vista similar cuando, ocho años antes, definió al urbanismo con estas palabras:

el espíritu humano que se concentra en el estudio de la compleja vida de los grandes centros urbanos, permitido por las observaciones acumuladas en la multitud de documentos que la historia nos ofrece, y en especial en los datos que dan las estadísticas desde tiempos antiguos, podemos decir que fundamentó exitosamente las bases de la nueva ciencia, que empieza a fructificar para proporcionar innegables servicios a la humanidad. ${ }^{51}$

Las representaciones de los urbanistas van más lejos, al considerar lo sólo científico como insuficiente. Era necesario impulsar a la ciencia a sus límites, aplicarla en todos los campos. En este empeño por ampliar el alcance de la razón para la acción, las ideas desarrolladas por Taylor tuvieron un papel importante. La participación del ingeniero Enrique Doria en el Congresso de Habitação (Congreso de Vivienda) en 1931, un año de recesión y por lo tanto de carencias en la producción de bienes y servicios, en un momento en que la penuria de 1929 se hallaba todavía en el aire, es como una perla en las cristalinas aguas de este mar de positivismo:

\footnotetext{
so Silva, "Typo", 1931 , p. 149.

51 Godoy, "Algumas", 1923 , p. 39.
}

Todo dependerá de la organización científica, del taylorismo en acción.

Ciencia en vez de empirismo;

Armonía en vez de discordancia;

Cooperación en vez de individualismo;

Máxima ganancia en vez de producción reducida;

Preparación de cada hombre;

para proporcionarle ganancia y máxima prosperidad. $^{52}$

La racionalización taylorista tuvo otro gran momento con los urbanistas brasileños. Diez años antes, las Jornadas de Habitação (Talleres de Vivienda) patrocinadas por IDORT, el Instituto de Racionalização e Organização do Trabalho (Instituto para la Racionalización y la Organización del Trabajo), tuvieron lugar simultáneamente en dos ciudades diferentes. El nombre de la institución, fundada en 1931, revelaba sus intenciones: racionalizar los métodos de construcción y llevar al taylorismo a los sitios de construcción. El taylorismo era una idea central en la práctica de la planeación de ciudades. Desde finales de los años veinte no había plano de ciudad en el que la zonificación no se aplicara. Este tipo de instrumento-seleccionar partes de la ciudad para funciones particulares-, tiene implicaciones en el movimiento del cuerpo, en tanto que sólo ciertas actividades son permitidas, siendo por lo tanto una especie de biopoder, tal como lo examinó Foucault.

Aunque los países en cuestión no poseían todavía economías industriales en aquella época, y la mayoría de su población vivía en el campo a pesar del enorme

52 Dória, “Sugestões", 1931, p. 53. 
tamaño de sus ciudades más grandes, la idea de zonificación era altamente indicadora de la transposición de la racionalidad del sistema de producción industrial al urbanismo. Como en una fábrica, en donde cada paso del proceso de producción se toma separadamente, de acuerdo con la teoría fordista, la ciudad, por medio de la zonificación, tendría cada función urbana ocurriendo en partes específicas de su territorio:

Es necesario un nuevo orden, porque no podemos continuar con la hornilla en la sala de estar, la cama en el comedor y el clóset en la cocina; nuestras ciudades se parecen en esto a la fábrica en el distrito de viviendas, el hospital en la zona comercial, y la escuela en una superficie temblorosa y tumultuosa. En la vida doméstica esto es anarquía y desorden. En la vida urbana esto es ruido, embotellamientos de tránsito, falta de higiene o, en otras palabras, "déficit", pandemónium y falta de sanitación. ${ }^{53}$

\section{URBANISTAS Y PODER}

Paralelamente a este proceso, tuvo lugar otro movimiento, uno de crítica a la administración urbana y por medio de ella al gobierno. Un ingeniero en el Primer Congreso Argentino de Urbanismo en 1935 observó:

Frecuentemente nos encontramos en las municipalidades con gente que tiene un criterio personal respecto a los problemas inherentes en la ciudad. Influenciados por factores políticos, autorizan concesiones o implementan ciertos trabajos, a veces ino-

${ }^{53}$ Cavalcanti, "Congreso", 1942, p. 45. portunos o precipitados, sin tomar en cuenta las prioridades [...] forzando a la misma ciudad a pagar una suma exorbitante en detrimento de su economía a causa de una dirección sin sentido. ${ }^{54}$

Una de las justificaciones empleadas con mayor frecuencia para criticar al gobierno municipal era la sustitución de quienes estaban en el poder. El cambio de alcalde en una municipalidad significaba una interrupción en los trabajos públicos y su abandono. La aplicación de ideas a largo plazo como las características en los planes de urbanización nunca ocurría de esa manera. Las instituciones representativas, sociedades democráticas típicas, eran consideradas ineficientes a los ojos de los urbanistas. En Brasil, en 1940, un periodista de Urbanismo e Vią̧ão señaló:

De todas maneras, lo más importante no es diseñar el plan sino alcanzar la fase de ejecución [...] lo peor es cuando los administradores cambian y nadie quiere seguir las reglas adoptadas por sus predecesores. Diseñemos un plan, si es necesario, pero exijamos también la conveniencia de una nueva mentalidad que pueda ver los beneficios de la perseverancia. El ideal, en una acción de este tipo, es no gastar esfuerzos en actividades fragmentarias, sino definir las reglas generales y seguirlas inflexiblemente, por décadas y décadas. ${ }^{55}$

Por consiguiente, la crítica de ineficacia se convierte en una negación de la democracia. En la mente de los urbanistas, se construye un modelo de gobierno. Este

\footnotetext{
${ }^{54}$ Suffriti, "Estudios", 1937, p. 131.

ss Anonymous, "Plano", 1940, p. 237.
} 
gobierno se suponía fuerte, autoritario y centralizado, con sólo profesionistas en los puestos principales. Las elecciones, la manera en la que aquellos que a veces representan los intereses de la población pero no son especialistas pueden acceder al poder, no son vistas como elementos positivos en política. Alguien que había estado en las oficinas del Grêmio Polytechnico en São Paulo en 1911, habría atendido a estas ideas proclamadas por un conferencista invitado, quien aprovecharía su erudición en la experiencia internacional para nutrir su argumento:

La administración municipal, en Gran Bretaña, es manejada por hombres de negocio: los concejales de la ciudad son reclutados casi exclusivamente entre comerciantes, industriales y jefes de compañías. Ser elegido concejal se considera una auténtica distinción, premiada por las clases que representan el papel de la aglomeración en las fuerzas económicas de la nación. Esta elección es tradicionalmente independiente de cualquier diferencia en creencias políticas. El proceso de elección es muy sencillo [...] la ley dictamina que cuando sólo hay un candidato deberá directamente considerarse elegido, el porcentaje de votos de una elección es bajo, aun en tiempos en que hay mayor efervescencia en la lucha de partidos. De esta manera, los nombres designados son confiados a los ciudadanos [...] Es muy común encontrar a un alcalde que permanece veinte o treinta años ininterrumpidos en el puesto [...] Este factor de competencia es lo que permite a las municipalidades inglesas y alemanas resolver las cuestiones más complicadas de manera rápida y eficiente. En cada puesto está el hombre adecuado. Son raras las polémicas sobre el servicio ofrecido: aquel que está en el gobierno es quien más sabe [...] Durante este tiempo el Consejo Municipal de París se hizo impotente con largos debates. Es por esto que, a pesar de la precisa naturaleza e inteligencia de la raza, es muy fácil a un incompetente alcanzar el puesto de concejal. ${ }^{56}$

No es difícil ver qué clase de régimen político sería apreciado de acuerdo con estas ideas. En un gobierno en el que hay una completa continuidad no hay espacio para la democracia ni necesidad de elecciones. El régimen político que corresponde a este cuadro es una dictadura. De hecho, la historia ha mostrado que era exactamente este tipo de gobierno el que adoptó Brasil con el golpe de Estado de 1937 , invitando a los urbanistas a convertirse en alcaldes y, al hacerlo, ganarse su apoyo. José Estelita, director de la Secretaria de Viação e Obras Públicas en el estado de Pernambuco, vio este proceso de la siguiente manera:

En el pasado, antes del golpe de Estado del 10 de noviembre de 1937, la politicagem (mala política) dominaba las ciudades; en donde la política crecía y se desenvolvía no podía existir ni disciplina ni respeto por la ley. La carencia urbana de disciplina era un reflejo de la falta general de disciplina en el país. Antes del Estado Novo, hablar de urbanismo, la ciencia que puede definirse como una coordinación disciplinaria, la ciencia que es la perfecta relación entre las cosas, hubiera sido utópico. Hoy, de todas formas, el ambiente es diferente y podemos ya intercambiar ideas en congresos y adoptar con ventaja medidas para sanear las ciudades. ${ }^{57}$

${ }^{56}$ Freire, "Melhoramentos", 1911, pp. 95-96.

57 Estelita, "Fala", 1941, p. 44. 


\section{SECUENCIG}
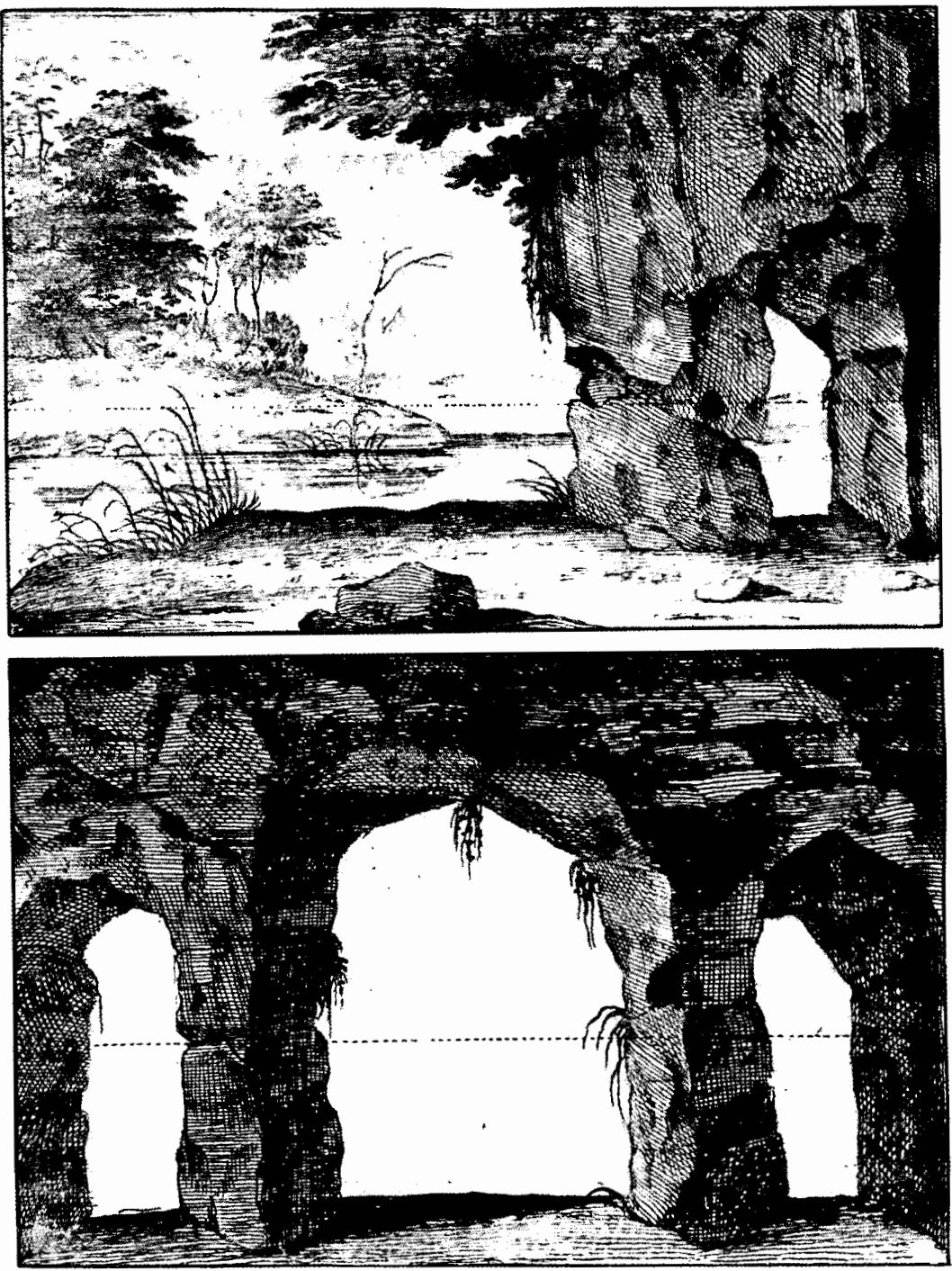


\section{CONSTRUYENDO LA NACIÓN}

El Zeitgeist de ese periodo estaba investido de otro elemento: el nacionalismo. Del lado brasileño se puede citar como ejemplo de su ola nacionalista la erudición de Alberto Torres, caracterizada con libros como $O$ problema nacional brasileiro y $A$ organizaşão nacional; la fundación de la Liga de Defesa Nacional creada en São Paulo por el poeta Olavo Bilac, quien pedía un papel educativo para el ejército; la fundación de la Revista do Brasil; la fundación del Partido Comunista en 1922; la rebelión de tenientes; la semana de artes modernas en São Paulo, y el movimiento integralista, una versión brasileña del fascismo. ${ }^{58}$

En el lado argentino tuvieron lugar eventos similares, como la fundación de la Liga Patriótica Argentina en 1919; nuevos estudios históricos de los años 1930 se centraron en una crítica al imperialismo británico en el país; la fundación en 1935 de un movimiento de jóvenes nacionalistas, FORJA, Fuerza de Orientación Radical de la Juventud Argentina, y la oposición política al monopolio del servicio de tranvías por compañías inglesas. ${ }^{59}$

En el discurso de los urbanistas, el nacionalismo aparecía al menos en dos for-

${ }^{58}$ Para una discusión general del tema véase Hobsbawn, Nations, 1990. Para una descripción de algunos aspectos en Brasil véase Pécaut, Peuple, 1989, pp. 15-19. Para un análisis véanse varios capítulos en Fausto, História, 1977, 2a. parte.

${ }^{59}$ Para el nacionalismo argentino en general véase Rock, Argentina, 1988, pp. 228-231, y Baily, Labor, 1967. Para la Liga véase Mcgee, "Visible", 1984, y Rock, Politics, 1975, pp. 181-189. Para la oposición a los tranvías ingleses véase Walter, "Municipal", 1974. mas diferentes. La primera era la idea de una arquitectura y un urbanismo nacionales, regionales y hasta autóctonos. Se puede encontrar esta idea en una de las ponencias presentadas en el Primeiro Congresso Brasileiro de Urbanismo:

Nuestros profesionistas, basados en literatura extranjera, suelen pensar con datos europeos y americanos, identificándose ellos mismos con las soluciones de estos países. Viajan para estudiar y a veces adquirir el espíritu de desprecio por nuestra falta de desarrollo y, no raramente, el bromista espíritu del científico que conoce las grandes soluciones, resultando siempre un desprecio por el estudio de nuestro medio. No aceptamos el absurdo de condenar el viajar o a la cultura extranjera -sabemos que son indispensables y esclarecedores-, pero lo que es necesario es que con estos viajes y con esa cultura saquemos provecho de la experiencia extranjera, y no escapemos de la nuestra. No debemos olvidar que se deben dar soluciones a nuestras necesidades, según nuestros recursos y adaptados a los hábitos de nuestra población y no sólo copiados de fuera. ${ }^{60}$

La idea de un urbanismo nacional, brasileño, adaptado a las playas, selvas y planicies de su territorio, de acuerdo con las costumbres y tradiciones del país, era muy claro en el discurso del ingeniero Jerónimo Cavalcanti durante un almuerzo de despedida antes de su viaje a Belém, en la región amazónica, en donde había sido designado para ocuparse de la alcaldía. El nuevo alcalde observó:

${ }^{60}$ Bueno y Bueno, "Alguns", 1941, p. 33. 
No voy a hacer urbanismo importado. Voy a hacer urbanismo autóctono basado en la antropología de la ciudad, con las tendencias de su gente, su historia y su hábitat, y a diseñar un plan fundado en su pasado y su tradición, que satisfará las necesidades presentes y abrirá el camino al futuro. ${ }^{61}$

Otra manera de expresar el sentimiento nacionalista es utilizando su capacidad laboral. En naciones de antigüedad de apenas 400 años, el futuro está todavía por construirse, grandes territorios deben ser poblados y tierras vírgenes colonizadas. Las bases de un gran país deben fundarse por medio de la construcción de nuevos centros de civilización: las ciudades. En este sentido, el papel del trabajador nacional debe ser reconsiderado. La construcción de una nueva ciudad, Goiania, era una buena oportunidad para este tipo de nacionalismo:

Desde este punto de vista podemos decir -y enorgullecernos de ello- que utilizando nuestras capacidades, podemos ejecutar numerosas cosas que los escépticos consideran utópicas. Cuando iniciamos Goiania todo mundo se rió con sarcasmo y duda. Este desprecio, este sarcasmo, provocó numerosos desencantos. Muchos perdieron la fe en la victoria, abandonando la lucha a medio camino, y desertaron de nuestra caravana. Por otra parte, el mismo sarcasmo, el mismo desprecio, la misma lucha fortalecieron la cohesión del pequeño grupo que luchaba para construir Goiania. No éramos numerosos en ese grupo y dimos un muy vívido ejemplo de lo que nosotros, los brasileños, podemos hacer con nuestra fuerza sola si decididamente queremos luchar. ${ }^{62}$

${ }^{61}$ Cavalcanti, "Plano", 1943, p. 34.

${ }^{62}$ Bueno y Bueno, "Alguns", 1941, p. 33.
LA CIUDAD: ¿UN SITIO PARA

LA DEGENERACIÓN?

Los problemas raciales fueron también tomados en consideración en la construcción de la identidad nacional. Especialmente en Brasil, donde hay una mezcla racial de los esclavos negros importados de África, la población indígena y los colonizadores portugueses blancos, el proyecto nacional se construyó por medio de un intento de justificar este crisol bajo la égida de la falsa idea de la democracia racial y la ausencia de discriminación. Aunque la mezcla étnica de individuos era considerada positiva, la idea de mejorar la raza nacional no estaba ausente. ${ }^{63} \mathrm{La}$ eugenesia, la idea de mejorar la raza, constituía un rasgo frecuente en el discurso urbano. Desde el más general punto de vista de la salud pública, en particular tras el Terceiro Congresso Brasileiro de Hygiene efectuado en 1926, la eugenesia se convirtió en una de las palabras clave de mayor fuerza en el movimiento higiénico. En 1929 tuvo lugar el Primeiro Congresso Brasileiro de Eugenismo.

Estas ideas envenenaron el discurso de los urbanistas. La mejoría de la raza requería eliminar el aislamiento racial, que se consideraba un posible retorno a la vida primitiva y a los hábitos tribales. Este asunto aparece a veces junto a un análisis psiquiátrico de la sociedad. Entre los urbanistas, la alusión más directa a éste fue hecha por miembros del Club Rotario de Río de Janeiro:

El elemento étnico dominante en las favelas son los negros, a quienes se alían otros ele-

${ }^{63}$ Sobre la mejoría racial véase Stepan, Hour, 1991. 
mentos alejados. La tendencia de los negros a aislarse de la civilización, a la que no quieren ser subyugados, es una corriente observable de hecho en las repúblicas de América del Sur. Entre nosotros, se manifiesta de una manera ostensible, debido a la ausencia de medidas coercitivas. Devuelta a su expresión rural, satisface impulsos violentos del subconsciente. El retorno a la vida primitiva permite a los negros satisfacer sus tendencias raciales, sus prácticas fetichistas, sus bailes y el macumba. Las favelas de Río, así como los mocambos de Recife, son raras reliquias africanas. ${ }^{64}$

Si las favelas y las viviendas insalubres de los pobres son descritas como negativas y teniendo un matiz racial, las políticas de urbanismo y de vivienda fueron pintadas como el reverso de la moneda:

La vivienda social no resuelve simplemente los problemas de los habitantes. La cuestión debe considerarse desde un punto de vista social. El desarrollo de la raza depende también de ello. De la vida promiscua de los cortiços salieron pandillas de pervertidos y delincuentes, contaminados por terribles enfermedades. La casa individual, ventilada e iluminada, salubre y apacible, es la celula mater de las razas fuertes. ${ }^{65}$

El concepto de degeneración, empleado en la construcción de la ciudad como problema social, era parte del paisaje cultural sudamericano del siglo Xx. La cuestión social estaba representada por la metáfora de una enfermedad hereditaria

${ }^{64}$ Mariano Filho, Amarante y Campello, "Problema", 1941, p. 53.

65 Albuquerque, "Sessão", 1931, p. 22. progresiva que contamina el cuerpo. Se suponía que la vida bajo ciertas condiciones físicas debilitaba la salud y la energía humana. Según esta representación, de una generación a la otra los descendientes se vuelven cada vez más débiles, enfermos, sin deseos de trabajar, inútiles para la sociedad. ${ }^{66}$ Nuevamente las ideas sobre la cuestión social se encuentran en el discurso de los urbanistas:

La vivienda insalubre tiene muchos inconvenientes: decadencia moral, decadencia física y decadencia biológica, transmitiendo a las siguientes generaciones los errores desastrosos de los que no son responsables quienes los adquieren en el presente. Una familia que vive en la promiscuidad de una casa que carece de la comodidad más rudimentaria, perpetuando el drama senzalas en el siglo $\mathrm{xx}$, degenera física y moralmente. ${ }^{67}$

Semejante representación es tan influyente que, en el texto escrito por Carlos Maria della Paolera cuando creó el símbolo del urbanismo, la idea se expresa por su opuesto: mejoría, regeneración:

La conquista de la naturaleza por la ciudad es un prometedor don de salud y belleza para los urbanistas. Las siguientes generaciones apreciarán los resultados de los prodigiosos esfuerzos de los urbanistas en esta cruzada para regenerar las condiciones de vida de la sociedad humana. ${ }^{68}$

${ }^{66}$ Para una discusión de estas ideas véase Borges, "Puffy", 1993, y Zimmermann, "Racial", 1992.

${ }^{67}$ Oliveira, "Estado", 1940, p. 195. Senzala era el sitio donde los esclavos vivían en las granjas del Brasil colonial.

${ }^{68}$ Paolera y Continentino, "Urbanismo", 1940, pp. 223-224. 


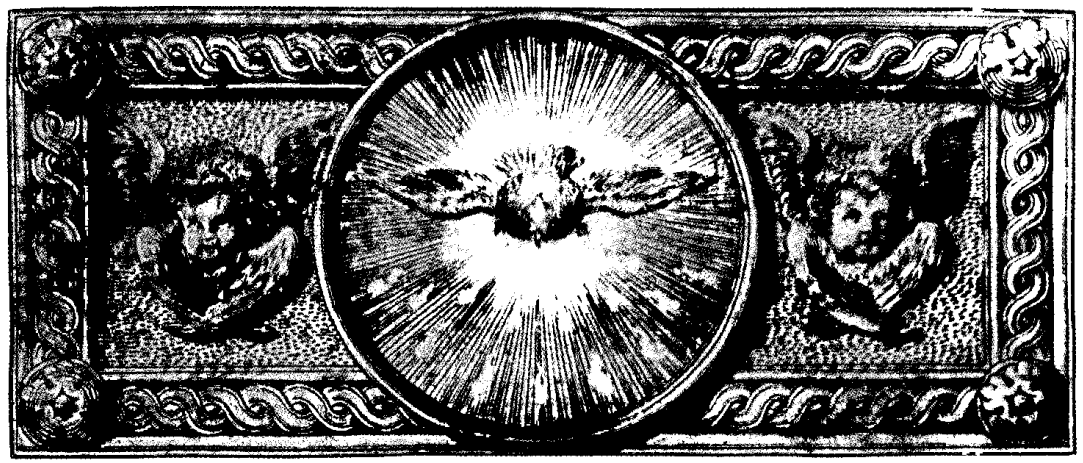

\section{CONCLUSIÓN}

Como en el caso de las prisiones, discutido por Foucault, el nacimiento del urbanismo está ligado a un proyecto para la transformación de los individuos. La manera en que son descritos los criminales en la disertación de criminología, o hasta en las páginas relacionadas con ello en los diarios, se parece muy de cerca a la forma en que fueron descritas por los urbanistas las habitaciones de los miserables. Foucault explica la descripción de los criminales como una forma de constituir al pueblo como un cuerpo moral separado de la delincuencia. En una sociedad industrial, en donde se requiere que parte de la riqueza no esté en manos de quien la posee, sino en las manos de quienes la hacen producir, permitiendo por lo tanto la extracción de ganancias, la constitución del pueblo como un cuerpo moral es vista como una forma de proteger su riqueza. ${ }^{69} \mathrm{En}$ forma similar, la descrip-

${ }^{69}$ Foucault, "Entretiens", 1975, pp. 132-133. ción del pobre urbano como un degenerado es una manera de proteger la riqueza invertida en la ciudad, la cual está a veces colocada en espacios desprotegidos y puede ser dañada fácilmente. Es también una manera de justificar la intervención en áreas malogradas para mejorarlas con la construcción de un entorno renovado, en concordancia con las necesidades de la acumulación de capital.

Las respuestas a estas cuestiones fueron halladas por medio de la genealogía del urbanismo, la cual hice con "una forma de historia que puede dar cuenta de la constitución del conocimiento, las disertaciones y los campos de acción de los objetos" ${ }^{70}$ Al escribir sobre prisiones, Foucault declara que los delincuentes son descritos como peligrosos e inmorales, para lograr con eso que la clase trabajadora los tema y se mantenga alejada de ellos. Señala que el papel de las páginas del crimen en los diarios es una herramienta para la construcción de esta ima-

${ }^{70}$ Foucault, "Nietzche", 1971, pp. 15-38. 
gen. Si comparamos esto con la representación de los urbanistas, vemos que quienes viven en los barrios pobres en ciudades no planificadas son descritos de manera semejante. La propaganda fue parte del movimiento urbanista. La presencia de reporteros en comisiones de urbanismo, como en el caso de Recife, así como la cobertura de ciertos diarios presentando el estado de las discusiones urbanistas, parece ser una buena evidencia de esto. Las entrevistas con los urbanistas se publicaron en los diarios y muchos de ellos dieron conferencias radiadas definiendo los principios urbanísticos. El discurso citado al principio de este artículo, por ejemplo, fue radiado. Es importante y fascinante el estudio del discurso de los urbanistas. Para mí, en parte revela cómo se pensó que la sociedad estaba conformada de acuerdo con los principios de la lógica industrial, o, al menos, cómo se hicieron algunos intentos para conformarla de esa manera, como es el caso de la planeación de ciudades.

\section{BIBLIOGRAFÍA}

-Abreu, M. A., Evolução Urbana do Rio de Janeiro, IPLANRio-Jorge Zahar Editor, 2a. ed., Río de Janeiro, 1988.

-Agache, D. A. H., Cidade do Rio de Janeiro: extensão, remodelação, embellezamento, Foyer Brésilien, París, 1930.

-Albuquerque, A., "Sessão inaugural" en Instituto de Engenharia de São Paulo, Annaes do I Congresso de Habitação, Escolas Profissionaes do Lyceu Coração de Jesus, São Paulo, 1931, pp. 21-23.

-Anonymous, "Annuaire 1906", La Technologie Sanitaire, enero, 1907.
-Anonymous, "Annuaire 1911", La Technique Sanitaire et Municipale, enero, 1912.

-Anonymous, "O plano da cidade", Urbanismo e Viaf̧ão, vol. 3, núm. 8, abril, 1940, p. 237.

-Anonymous, "Um pintor chamado Prestes Maia", Cidade, vol. 3, núm. 4, 1996, pp. 60-75.

-Baily, S. L., Labor, nationalism and politics in Argentina, Rutgers University Press, New Brunswick, 1967.

-Baltar, Antonio B., "Diretrizes de um plano regional para o Recife", tesis de cátedra, Ed. Universitaria, Recife, 1951.

-Barbosa, J. L., "Modernização urbana e movimento operário", tesis de maestría, IG-LIERJ, Río de Janeiro, 1990.

-Benchimol, J. L., "Pereira Passos: um Haussmann Tropical, as transformações urbanas do Rio de Janeiro no inicio do século Xx", tesis de maestría, COPPE-UFRJ, Río de Janeiro, 1982.

-Biagini, H., El movimiento positivista argentino, Editorial de Belgrano, Buenos Aires, 1985.

-Bodstein, R. C. A., "Práticas sanitárias e classes populares do Rio de Janeiro", Revista Río de Janeiro, vol. 1, núm. 4, 1986, pp. 33-43.

-Borges, D., 'Puffy, ugly, slothful and inert': degeneration in Brazilian social thought, 18801940", Journal of Latin American Studies, núm. 25, vol. 2, 1993, pp. 235-256.

-Bourdé, Guy, Buenos Aires: inmigración y urbanización, Editorial Huemul S. A., Buenos Aires, 1977.

-Bragos, O., "El urbanismo francés en América Latina: D. A. Agache en Río de Janeiro, J. C. N. Forestier en Buenos Aires", Cuadernos del CURDIUR, núm. 54, 1991.

-Brito, F. R. S., Saneamento do Recife, Typographia da Imprensa Official, Recife, 1917, 2 vols.

-Bueno, A. C. y J. C. Bueno, "Alguns aspectos dos problemas de urbanismo: tese apresentada ao I Congresso Brasileiro de Urbanismo pelos engenheiros J. e A. Coimbra Bueno", Ur- 
banismo e Viação, vol. 4, núms. 15-16, septiembre, 1941, pp. 33-34.

-Cafferata, J., "I Congresso Pan-Americano da Vivenda Popular", Urbanismo e Viaf̧ão, vol. 2, núm. 6, diciembre, 1939, pp. 161-165.

-Campos, E., "São Paulo na visão classi[ci]sta de Prestes Maia", Cidade, vol. 3, núm.4, 1996, pp. 42-45.

-Carvalho, R. C. M., "Urban Planning in Rio de Janeiro: A Study of the Urban Redevelopment Plan During the Passos Administration (1902-1906)", tesis de maestría, Cornell University, Ithaca, NuevaYork, 1984.

—_, "The Search for a Modern City:

The Urban Renewal Plan for Rio de Janeiro, 1902-1906", Colloqui: A Joumal of Planning and Urban Issues, primavera, 1988, pp. 8-17.

-Cavalcanti, J., "II Congresso Brasileiro de Urbanismo", Urbanismo e Viação, vol. 5, núm. 20, agosto, 1942 , pp. 20 y 45.

_, "O Plano de remodelação de Belém", Urbanismo e Viação, vol. 6, núm. 26, abrilmayo, 1943, pp. 33-34.

-Connif, Michael L., Melvin Hendrix y Stephen Nohlgren, "Brazil" en Richard M. Morse, M. Connif y J. Wibel, Urban, 1971.

-Chanourdie, E., "La transformación edilicia de Buenos Aires", Arquitectura, vol. 3, núm. 39, 1906-1907, pp. 95-103.

-Commissao de Melhoramentos da cidade do Rio de Janeiro, J. R. M. Jardim y M. R. Silva, Primeiro relatorio da Commissão de Melboramentos da Cidade do Rio de Janeiro, Imprensa $\mathrm{Na-}$ cional, Río de Janeiro, 1875.

- Segundo relatorio da Commissão de Melboramentos da Cidade do Rio de Janeiro, Imprensa Nacional, Río de Janeiro, 1876.

-Desplat, M., Mejoras urbanas, Talleres Gráficos de la Penitenciaría Nacional, Buenos Aires, 1906.

-Dótia, H., "Sugestões para a solução dos problemas das casas operárias" en Instituto de
Engenharia de São Paulo, Annaes do I Congresso de Habitação, Escolas Profissionaes do Lyceu Coração de Jesus, São Paulo, 1931, pp. 51-54.

-Driver, F., "Bodies in Space: Foucault's Account of Disciplinary Power" en C. Jones y R. Porter (eds.), Re-Assessing Foucault, reimpreso en G. Derek y T. Barnes (eds.), Reading Human Geography: The Poetics and Politics of Enquiry, Arnold, Londres, 1997, pp. 279-289.

-Eley, G. y K. Nield, "Starting Over: The Present, the Post-Modern and the Moment of Social History", Social History, vol. 20, núm. 3, 1995, pp. 355-365.

-Escobar, A., "Culture Sits in Places: Reflections on Globalism and Subaltern Strategies of Localization", Political Geography, vol. 20, núm. 2, 2001, pp. 139-174.

-, "Beyond the Search for a Para.. digm? Post-Development and Beyond", Development, vol. 43, núm. 4, 2000, pp. 11-14. , "Anthropology and Development", International Social Science Journal, núm. 154, 1997, pp. 497-516

- Encountering Development: The Making and Unmaking of the Third World, Princeton University Press, Princeton, 1995.

_- "Power and Visibility: Development and the Invention and Management of the Third World", Cultural Anthropology, vol. 3, núm. 4, 1988, pp. 428-443.

- "Discourse and Power in Development: Michel Foucault and the Relevance of his Work to the Third World", Alternatives, vol. 10, núm. 3, 1984-1985, pp. 377-400.

-Escobar, A. y B. Roberts, "Surveys as Instruments of Modernization: The Case of Mexico", American Behavioral Scientist, vol. 42, núm. 2, 1998, pp. 237-251.

-Estelita, J., "Os parques Norte-Americanos e o problema da criminalidade", Revista da Directoria de Engenbaria, vol. 2, núm. 17, 1935, pp. 424-426. 
-, "Fala á 'Urbanismo e Viação' o Representante de Pernambuco", Urbanismoe Vią̧ão, vol. 4, núm. 13, marzo, 1941, p. 44.

-Fausto, B. (ed.), História Geral da Civilização Brasileira: O Brasil republicano, sociedade e instituiçães (1889-1930), DIFEL, São Paulo, 1977, vol. 3, 2a. parte.

-Ficher, S., "Ensino e profissão: o curso de engenheiro-arquiteto da Escola Politécnica de São Paulo", tesis de doctorado, Departamento de Historia-Universidade de São Paulo, São Paulo, 1989, 2 vols.

-Foucault, M., "Politics and the study of discourse" [1968] en C. Gordon, P. Miller y G. Burchell, The Foucault Effect: Studies in Governmentality, with Two Lectures by and an Interview with Michel Foucault, Wheatsheaf, Havester, 1991, pp. 53-72.

- Microfísica do poder, Graal, 9a. ed., Río de Janeiro [1979], 1990.

- "Nietzche, la génealogie, l'histoire" en Hommage à Jean Hyppolite, Presse Universitaire de France, París, 1971, traducido por M. Catan como "Nietzche, a genealogia e a história” en Foucault, Microfísica, 1990, pp. 15-38.

- "O nascimento da medicina social" [1974] en Foucault, Microfísica, 1990, pp. 79-98. - Surveiller et Punir: naissance de la prison, Gallimard, París, 1975.

—, "Entretiens sur la prision: le livre et sa méthode", Magazine Littéraire, núm. 101, 1975 , traducido por M. M. Damião como "Sobre a prisão" en Foucault, Microfísica, 1990, pp. 129-144.

-, "Verité et pouvoir", L'Arc, núm. 70, [1977], pp. 1-14, traducido por Holzmeister y Souza como "Verdade e poder" en Foucault, Microfísica, 1990, pp. 4-5.

, "La poussière et le nuage" en $M$. Perrot (ed.), L'impossible prison: recherches sur le système pénitentiaire au XIXe siècle, Editions du Seuil, París, 1980, pp. 29-39.
- "Table ronde du 20 mai 1978" en M. Perrot (ed.), L'impossible prison: recherches sur Le système pénitentiaire au XIXe siècle, Editions du Seuil, París, 1980, pp. 40-58.

-Freire, V. S., "Melhoramentos de São Paulo", Revista Polytechnica, núm. 33, 1911, pp. 91 145.

-Gantos, M. C., "Progresso e crise urbana: a Comissão de Melhoramentos da Cidade do Rio de Janeiro (1870-1876)", tesis de maestría, Departamento de Historia-UFF, Niterói, 1993.

-Godoy, A. A., "Algumas idéias sobre a remodelação das cidades" en Sociedade Brasileira de Hygiene, Annaes do Primeiro Congresso Brasileiro de Hygiene, Río de Janeiro, 1923, pp. 39-47.

-Greenfield, G. M., "Privatism and Urban Development in Latin America: The Case of São Paulo, Brazil", Journal of Urban History, vol. 8, núm. 4, 1982, pp. 397-426.

—. "Patterns of Enterprise in São Paulo: Preliminary Analysis of a Late Nineteenth Century City", Social Science History, vol. 8, núm. 3, 1984, pp. 291-312.

-Hale, C., "Political and social ideas" en L. Bethell (ed.), The Cambridge History of Latin America, Cambridge University Press, Cambridge, 1988, vol. 4, pp. 225-299.

-Hardoy, J. E. "Theory and Practice of Urban Planning in Europe (1850-1930): Its Transfer to Latin America" en J. E. Hardoy y R. Morse (eds.), Retbinking the Latin American City, JHUP, Londres y Baltimore, 1992, pp. 20-49.

y R. Morse (eds.), Retbinking the Latin American City, JHUP, Londres y Baltimore, 1992.

-Hardoy, J. E. et al., "Evolución de Buenos Aires en el tiempo y en el espacio", Revista de Arquitectura, vol. 40, núms. 375 y 376-377, 1955, pp. 25-84 y 25-125.

-Hobsbawn, E. J., Nations and nationalisms since 1780: programme, myth, reality, Cambridge University Press, Cambridge, 1990. 
-Kessel, M. I., "Crescimento urbano e reforma urbana em metrópole não industrial: o caso do Rio de Janeiro no periodo 1870-1920", tesis de maestría, DCS-PUC, São Paulo, 1983.

-Laks, Nathan, "Argentina" en Richard M. Morse, M. Connif y J. Wibel, Urban, 1971.

-Léonard, J., "L'historien et le philosophe: à propos de Surveiller et Punir; naissance de la prison" en M. Perrot (ed.), L'impossible prison: recherches sur le système pénitentiaire au XIXe sièdle, Editions du Seuil, París, 1980, pp. 9-28.

-Lubambo, C. W., Do Corpo Santo ao Marco Zero: o bairro do Recife no inicio do século, uma experiência de modernização urbana, Massangana, Recife, [1988], 1991.

-Maia, F. P., Estudo de um Plano de Avenidas para a cidade de São Paulo, Companhia Melhoramentos, São Paulo, 1930. , "A remodelação de São Paulo", $R e$ vista do Club de Engenharia, 2F, vol. 7, núm. 72, 1941, pp. 3-16.

, Os melboramentos de São Paulo, Prefeitura Municipal de São Paulo, São Paulo, 1945.

-Marianno Filho, J., "A technica do mocambo", Urbanismo e Viação, vol. 2, núm. 6, diciembre, 1939, pp. 169-170.

A. P. Amarante y A. Campello, "O problema das favelas do Rio de Janeiro: contribuição do Rotary Club ao $1^{\circ}$ Congresso Brasileiro de Urbanismo", Urbanismo e Vią̧ão, vol. 4, núm. 13, marzo, 1941, pp. 52-53 y 72.

-Mcdowall, D., The Light: Brazilian Traction, Light and Power Company Limited, University of Toronto Press, Toronto, 1988.

-Mcgee, S. F., "The visible and invisible Liga Patriótica Argentina, 1919-28: gender roles and the right wing", Hispanic American Historical Review, vol. 64, núm. 2, 1984, pp. 233-258.

-Meade, T., "Civilizing Rio": Reform and Resistance in a Brazilian City (1889-1930), Pennsylvania State University Press, University Park, 1997.
-Mendonça, M. T. C., "Casas populares: cidades jardins" en Instituto de Engenharia de São Paulo, Annaes do I Congresso de Habitação, Escolas Profissionais do Lyceu Coração de Jesus, São Paulo, 1931, pp. 139-147.

-Morse, Richard M., M. Connif y J. Wibel, The urban development of Latin America, Center for Latin American Studies, Stanford, 1971.

-Mota, A., No tempo do bonde elétrico, Celpe, 2a. ed., Recife, 1985.

-Nachman, R. G., "Positivism and the middle class in Brazil", Hispanic American Historical Review, núm. 57, 1977, pp. 1-23.

-Needell, J. F., "Rio de Janeiro at the Turn of the Century: Modernization and the Parisian Ideal", Journal of Interamerican Studies and World Affairs, vol. 25, núm.1, 1983, pp. 83-103. , A Tropical Belle Epoque: Elite Culture and Society in Turn-of-the-Century Rio de Janeiro, cuP, Cambridge, 1987.

"Rio de Janeiro and Buenos Aires: Public Spaces and Public Consciousness in Finde-Siècle Latin America", Comparative Studies in Society and History, vol. 37, núm. 3, 1995, pp. 519-540.

-Noiriel, G., "Foucault and History: The Lessons of a Disillusion", Journal of Modern History, núm. 66, 1994, pp. 547-568.

-Novick, A., "Técnicos locales y extranjeros en la génesis del urbanismo argentino, Buenos Aires, 1880-1940", ponencia no publicada, Buenos Aires, 1990.

_- "Técnicos locales y extranjeros en la génesis del urbanismo porteño, Buenos Aires, 1880-1940", Área. Revista de Investigaciones, Facultad de Arquitectura, Diseño y Urbanismo, FADU-UBA/Ecole Polytechnique Fédérale de Lausanne, núm. 1, diciembre, 1992, pp. 29-51.

-Nunes, L. A. P., "Prestes Maia na História do Planejamento de Santos" en D. B. P. Machado (ed.), Anais do IV Seminário de História da Cidade e do Urbanismo, Río de Janeiro, 1996, pp. 86-97. 
-Oliveira, F. B. de, "La casa proletaria", Urbanismo e Viaģão, vol. 3, núm. 7, enero, 1940, pp. 187-197.

" "O estado actual da vivenda popular na América", Urbanismo e Viaģão, vol. 3, núm. 7, enero, 1940, pp. 199-208.

, "A casa popular e o aspecto urbanístico das cidades", Urbanismo e Viaçãa, vol. 3, núm. 7, enero, 1940, pp. 209-214.

"Acesso do povo à casa própria", Urbanismo e Viação, vol. 4, núm. 16, septiembre, 1941, p. 19.

-Osello, M. A., "Planejamento urbano em São Paulo (1889-1961): introdução ao estudo dos planos e realizações", tesis de maestría, EAESP-FGV, São Paulo, 1983.

-Outtes, J., "O Recife pregado à cruz das grandes avenidas: contribuição à história do urbanismo (1927-1945)", tesis de maestría, MDUUFPE, Recife, 1991, próxima aparición en Ed. Massangana, Recife.

$\longrightarrow$, La ville: lieu de la dégénérescence? urbanisme et représentations sociales au Brésil et en Argentine (1920-1945), Mémoire de DEA, Ecole des Hautes Etudes en Sciences Sociales-Centre de Sociologie Urbaine-CNRS, París, 1993.

—_, O Recife: gênese do urbanismo, Massangana, Recife, 1997.

_- "Diciplining Society through the City? The Birth of Urbanismo (City Planning) in Brazil (1916-1941)", tesis de doctorado, Oriel College, Oxford, 1999.

-Palmer, B. D., Descent into Discourse: The Reification of Language and the Writing of Social History, Temple UP, Philadelphia, 1990.

-Paolera, C. M. della y L. Continentino, "Urbanismo -o plano de Belo Horizonte: impressões de uma viagem recente à Argentina", Arquitetura e Urbanismo, vol. 5, núm. 4, 1940, pp. 222-225.

-Pécaut, D., Entre le peuple et la nation: les intellectuels et la politique au Brésil, Editions de la Maison des Sciences de l'Homme, París, 1989.
-Pechmann, S., "Reformas urbanas e classes dominantes no Rio de Janeiro na virada do século: algumas anotações sobre o debate recente", artículo presentado en el VII Encontro Anual da Associação Nacional de Pós-Graduação e Pesquisa em Ciências Sociais, octubre 16-28, 1983, Águas de São Pedro-MG.

— y L. Fritsch, "A reforma urbana e o seu avesso: algumas considerações a propósito da modernização do Distrito Federal na virada do século", Revista Brasileira de História, vol. 5, núms. 8-9, septiembre 1984-abril 1985, pp. 139-195.

-Pereira, S. G., “A reforma urbana de Pereira Passos e a construção da identidade Carioca", tesis de doctorado, ECO-UFRJ, Río de Janeiro, [1992], 1996.

-Pontes, J. A. O. V., "Francisco Prestes Maia: o político que não gostava de política", Cidade, vol. 3, núm. 4, 1996, pp. 4-9.

-Poster, M., "Foucault and History", Social Research, vol. 49, núm. 1, 1982, pp. 116-142.

-Prado, R., "Urbanismo e a criança", Urbanismo e Vią̧ão, vol. 4, núm. 13, marzo, 1941.

-Prestes Maia, Francisco, Estudo de um plano de avenidas para a Cidade de São Paulo, Cia. Melhoramentos, São Paulo, 1930.

-Rock, D., Politics in Argentina (1890-1930): the rise and fall of radicalism, Cambridge University Press, Cambridge, 1975, pp. 181-189.

-, Argentina, 1516-1982: from Spanish colonization to the Falklands war, Cambridge University Press, Cambridge, 1988, pp. 228-231.

-Rolnik, R., "Cada um no seu lugar! São Paulo, inicio da industrialização: geografia do poder", tesis de maestría, FAU-USP, São Paulo, 1981.

-San Vicente, I. M., "Planes y proyectos para Rosario 1890-1910", Documentos de Arquitectura Nacional y Americana, núm. 21, 1986, pp. 89-95.

-Sargent, C. S., The Spatial Evolution of Greater Buenos Aires, Argentina, 1870-1930, Arizona State University, Tempe, 1974. 
-Scobie, J. R., Argentina: a city and a nation, Oxford University Press, Nueva York, 1971.

_ Buenos Aires: from plaza to suburb (1870-1910), Oxford University Press, New York, 1974.

-Silva, A. P., "Typo racional de habitação" en Instituto de Engenharia de São Paulo, Annaes do I Congresso de Habitação, Escolas Profissionaes do Lyceu Coração de Jesus, São Paulo, 1931, pp. 149-164.

-Simões, J. G., "O setor de obras publicas e as origens do urbanismo na cidade de São Paulo", tesis de maestría, EAESP-FGV, São Paulo, 1990.

-Souto, L. R. V., Melboramentos da Cidade do Rio de Janeiro: crítica dos trabalbos da respectiva commissão, Lino Teixeira, Río de Janeiro, 1875.

- Melboramentos da Cidade do Rio de Janeiro: refutação da resposta à crítica dos trabalhos da respectiva segunda commissão, Lino Teixeira, Río de Janeiro, 1876.

-Stepan, N., "The hour of eugenics": race, gender and nation in Latin America, Cornell University Press, Ithaca, 1991.

-Suffriti, C., "Estudios sobre urbanismo" en Obras Sanitarias de la Nación, Primer Congreso
Argentino de Urbanismo realizado en Buenos Aires los días 11 al 19 de octubre de 1935: contribución de Obras Sanitarias de la Nación, Imprenta Mercatali, Buenos Aires, 1937, pp. 131-138.

-Toledo, B. L., Prestes Maia e as origens do urbanismo moderno em São Paulo, Empresa das Artes, São Paulo, 1996.

-Walter, R. J., "Municipal politics and government in Buenos Aires, 1918-1930",Joumal of Inter American Studies and World Affairs, vol. 16, núm. 2, 1974, pp. 173-197.

-Walter, Richard J., "The socio-economic growth of Buenos Aires" en Thomas F. McGann y S. Stanley (eds.), Buenos Aires: 400 years, University of Texas Press, Austin, 1982.

-Zaidan, N., "O Recife nos trilhos dos bondes de burro (1871-1914)", tesis de maestría, MDU-UFPE, Recife, 1991.

-Zimmermann, E. A., "Racial ideas and social reform: Argentina, 1890-1916", Hispanic American Historical Review, vol. 72, núm. 1, 1992, pp. 23-46.

-Zmitrowicz, W., "O sonho e a realidade do 'Plano de Avenidas'", Cidade, vol. 3, núm. 4, 1996, pp. 28-35. 